Article

\title{
Cost-Effective and Time-Efficient Molecular Assisted Selection for PPV Resistance in Apricot Based on ParPMC2 Allele-Specific PCR
}

\author{
Ángela Polo-Oltra ${ }^{1}$, , Carlos Romero ${ }^{2}$, Inmaculada López ${ }^{1}$, María Luisa Badenes ${ }^{1}(\mathbb{C}$ \\ and Elena Zuriaga $1, *(\mathbb{D})$ \\ 1 Citriculture and Plant Production Center, Instituto Valenciano de Investigaciones Agrarias (IVIA), CV-315, \\ km 10.7, 46113 Moncada, Valencia, Spain; polo_ang@externos.gva.es (Á.P.-O.); lopez_inmcap@gva.es (I.L.); \\ badenes_mlu@gva.es (M.L.B.) \\ 2 Instituto de Biología Molecular y Celular de Plantas (IBMCP), Consejo Superior de Investigaciones \\ Científicas (CSIC)—Universidad Politécnica de Valencia (UPV), Ingeniero Fausto Elio s/n, \\ 46022 Valencia, Spain; cromero@ibmcp.upv.es \\ * Correspondence: garcia_zur@gva.es; Tel.: +34-963424040
}

Received: 31 July 2020; Accepted: 25 August 2020; Published: 31 August 2020

\begin{abstract}
Plum pox virus (PPV) is the most important limiting factor for apricot (Prunus armeniaca L.) production worldwide, and development of resistant cultivars has been proven to be the best solution in the long-term. However, just like in other woody species, apricot breeding is highly time and space demanding, and this is particularly true for PPV resistance phenotyping. Therefore, marker-assisted selection (MAS) may be very helpful to speed up breeding programs. Tightly linked ParPMC1 and ParPMC2, meprin and TRAF-C homology (MATH)-domain-containing genes have been proposed as host susceptibility genes required for PPV infection. Contribution of additional genes to PPV resistance cannot be discarded, but all available studies undoubtedly show a strong correlation between ParPMC2-resistant alleles (ParPMC2res) and PPV resistance. The ParPMC2res allele was shown to carry a 5-bp deletion (ParPMC2-del) within the second exon that has been characterized as a molecular marker suitable for MAS (PMC2). Based on this finding, we propose here a method for PPV resistance selection in apricot by combining high-throughput DNA extraction of 384 samples in 2 working days and the allele-specific genotyping of PMC2 on agarose gel. Moreover, the PMC2 genotype has been determined by PCR or by using whole-genome sequences (WGS) in 175 apricot accessions. These results were complemented with phenotypic and/or genotypic data available in the literature to reach a total of 325 apricot accessions. As a whole, we conclude that this is a time-efficient, cost-effective and straightforward method for PPV resistance screening that can be highly useful for apricot breeding programs.
\end{abstract}

Keywords: apricot; MAS; breeding; MATH; PPV resistance; agarose; ParPMC; ParPMC2-del

\section{Introduction}

Most cultivated apricots belong to the Prunus armeniaca L. species, a member of the Rosaceae family, Prunus genus and section Armeniaca (Lam.) Koch [1]. World apricot production reached 3.84 million tonnes in 2018, with Turkey, Uzbekistan and Iran as the main producers (http://www.fao.org/faostat/). This means an increase of about $45 \%$ since 1998 mainly due to Asian countries. By contrast, European production in this period has just increased slightly while the cultivated area declined up to $19 \%$. Despite its wide geographical spread, apricot has very specific ecological requirements. Consequently, each region usually grows locally adapted cultivars. For this reason, significant breeding efforts have been undertaken since the first apricot breeding program started in 1925 at the Nikita Botanical Garden 
in Yalta (Crimea, Ukraine) [2]. However, apricot breeding based on biparental controlled crosses and subsequent selection of the best new allelic combinations is hardly limited by the capacity to evaluate trees in the field [3]. On one side, fruit trees show high space requirements to be grown. On the other, their juvenile phase is quite long and reliable pomological phenotyping requires several cropping seasons, which means that at least ten years are needed to release a new variety. Therefore, the implementation of marker-assisted selection (MAS) has a great potential to improve breeding efficiency in fruit trees, including apricot.

Sharka disease, caused by Plum pox virus (PPV), is currently the most important viral disease affecting stone fruit trees (Prunus spp.) [4]. To date, nine PPV strains (D, M, C, EA, W, Rec, T, $\mathrm{CR}$ and An) are identified [5]. However, PPV genetic diversity may be even bigger, as observed by Chirkov et al. [6], who recently described the new Tat isolates affecting sour cherry (Prunus cerasus). PPV-D and $M$ are the most widespread and economically important strains [5,7]. A clear host preference is observed: PPV-D/plum/apricot and PPV-M/peach. However, underlying genetic determinants are still unknown [8].

Particularly in apricot, PPV-D has severely hindered production in the last three decades, especially in endemic areas. In this context, development of PPV-resistant varieties is the main objective of apricot breeding programs. However, resistant sources are scarce. Just a handful of North American PPV-resistant cultivars have been identified to date, and they are commonly used as donors in all apricot resistance breeding programs currently in progress [9]. Several independent works aimed at dissecting the genetic control of PPV resistance in apricot have identified the major dominant PPVres locus in the upper part of linkage group 1 [10-17]. According to the pedigree and fine mapping data, a single common ancestor carrying PPVres has been suggested for all PPV-resistant cultivars [16,18-20]. Moreover, other minor loci contributing to PPV resistance have been suggested [13-16], but their role has not yet been well defined. More recently, transcriptomic and genomic analyses of PPVres locus have pointed out ParPMC1 and ParPMC2, two members of a cluster of meprin and TRAF-C homology domain (MATHd)-containing genes, as host susceptibility paralogous genes required for PPV infection [21]. The ParPMC2 allele linked in coupling with PPV resistance (ParPMC2res) accumulates 15 variants, including a 5 nt deletion (ParPMC2-del) that results in a premature stop codon. Moreover, cultivars carrying the ParPMC2res allele show that ParPMC2 and especially ParPMC1 genes are downregulated. As a result, this ParPMC2res was proposed to be a pseudogene that confers PPV resistance by silencing functional homologs, the non-mutated ParPMC2 allele and/or ParPMC1. Another plausible scenario involves epigenetic modifications to explain ParPMC silencing in the resistant cultivars [22].

In spite of evidence supporting linkage with the PPVres locus, some genotype-phenotype incongruencies (GPIs) have been detected in biparental populations segregating for PPV resistance $[17,23,24]$. In other words, some phenotypically susceptible individuals carrying ParPMC2res were classified as genetically resistant. Possible causes underlying these discrepancies, including other loci contributing to PPV resistance, are still unresolved. However, the potential benefit of using a ParPMC2 allele-specific marker (PMC2) for MAS is still very high since sharka resistance phenotyping is a major bottleneck in apricot breeding programs. The most reliable method for apricot PPV resistance phenotyping is based on a biological test that uses GF-305 peach rootstocks as woody indicators and graft-inoculation with PPV [25]. This procedure is time-consuming and requires visual inspection during two to four growing seasons in several replicates per genotype followed by ELISA [26] and RT-PCR tests [27]. It should be noted that the plant to be tested must be of a significant size in order to have enough buds for grafting replicates, so it takes a couple of years from the time of crossing. As a result of a genetic mapping approach, Soriano et al. [18] reported the first successful MAS application for PPV resistance using 3 SSRs within the PPVres locus resolved by capillary electrophoresis. Afterwards, these SSRs were combined with a single sequence length polymorphism marker (ZP002) interrogating the ParPMC2-del resolved by capillary or acrylamide electrophoresis [24] and by high resolution 
melting [28]. However, specialized DNA testing services are needed to adopt these MAS approaches, and together with the economic costs, this could be a challenge [29].

Here, we report a method combining high-throughput DNA extraction of 384 samples in 2 days and PMC2 genotyping by allele-specific PCR amplification and agarose gel electrophoresis. This method is proven to be an easily implemented tool for MAS of PPV-resistant seedlings in almost any apricot breeding program. Therefore, bioassays for PPV resistance evaluation will be needed to confirm the phenotype in selected materials. Moreover, PMC2 genotype has been determined and/or revised for 325 worldwide cultivated apricot accessions providing useful information for breeders to select parental genotypes.

\section{Materials and Methods}

\subsection{High-Throughput DNA Isolation in 96-Well Plate}

The genomic DNA extraction protocol was optimized from the original Doyle and Doyle method [30] to manage 384 samples per isolation using 8-well 1.2-mL strip tubes (VWR International). For each accession, 2 leaf discs were collected and placed into a tube with 3 glass beads (VWR International). The strips were frozen in liquid $\mathrm{N} 2$ and stored at $-20^{\circ} \mathrm{C}$ before DNA isolation. Frozen tissue was ground for 1 min with a frequency of 26/s using a Qiagen TissueLyser 85210 (Qiagen, Hilden, Germany). Then, $340 \mu \mathrm{L}$ of preheated CTAB isolation buffer (with $0.2 \% 2$-mercaptoethanol) was added to the ground tissue and incubated at $65^{\circ} \mathrm{C}$ for $40 \mathrm{~min}$, shaking gently every $10 \mathrm{~min}$. After a short spin, $340 \mu \mathrm{L}$ of chloroform-isoamyl alcohol (24:1) was added and mixed inverting the plates. Tubes were centrifuged for $10 \mathrm{~min}$ at $3000 \mathrm{rpm}$ and $4{ }^{\circ} \mathrm{C}$. The clean aqueous phase was transferred to new strip tubes, and $1.5 \mathrm{vol}$ of $100 \%$ ethanol and $15 \mathrm{mM}$ ammonium acetate were added and mixed gently. After overnight incubation at $-20^{\circ} \mathrm{C}$, tubes were centrifuged for $10 \mathrm{~min}$ at $3000 \mathrm{rpm}$ at $4{ }^{\circ} \mathrm{C}$. The supernatant was discarded inverting the tubes, and $300 \mu \mathrm{L}$ of $70 \%$ ethanol was added. After centrifugation for $10 \mathrm{~min}$ at $3000 \mathrm{rpm}$ at $4{ }^{\circ} \mathrm{C}$, the supernatant was discarded and finally $75 \mu \mathrm{L}$ of TE was added. DNA at 1:10 dilution was used for PCR. Some random DNA samples from each plate were subjected to quality control. DNA integrity was checked on an agarose gel, and quantification was performed using a Nanodrop ND-1000 spectrophotometer (Nanodrop Technologies, Wilmington, DE, USA).

\subsection{PMC2 Genotype by Allele-Specific PCR Assay}

PMC2 marker genotyping was performed using the allele-specific forward primer (PMC2-F-alleleR: 5'-GTCATTTTCATTGATGTCATTCA-3' , or PMC2-F-alleleS: 5'-GTCGTTTTCATTGATGTCCAAAC-3' , respectively) and one common reverse primer (PMC2-R: 5'-GTGCTCTTTCACATTCTTGCTC-3'), as described by Zuriaga et al. [21]. PCRs were performed in a final volume of $20 \mu \mathrm{l}$ containing $1 \times$ DreamTaq buffer, $0.2 \mathrm{mM}$ of each dNTP, $5 \mu \mathrm{M}$ of each primer, $1 \mathrm{U}$ of DreamTaq DNA polymerase (Thermo Fisher) and $2 \mu \mathrm{L}$ of DNA extraction (diluted 1:10). Cycling conditions were as follows: an initial denaturing of $95^{\circ} \mathrm{C}$ for $5 \mathrm{~min} ; 35$ cycles of $95{ }^{\circ} \mathrm{C}$ for $30 \mathrm{~s}, 55^{\circ} \mathrm{C}$ for $45 \mathrm{~s}$ and $72{ }^{\circ} \mathrm{C}$ for $45 \mathrm{~s}$; and a final extension of $72{ }^{\circ} \mathrm{C}$ for $10 \mathrm{~min}$. PCR products were electrophoresed in $1 \%(\mathrm{w} / \mathrm{v})$ agarose gels.

Available DNA samples from 120 apricot cultivars and accessions were PCR screened in this work. Part of this collection is currently kept at the collection of the Instituto Valenciano de Investigaciones Agrarias (IVIA) in Valencia (Spain), while other samples were provided by the Departamento de Mejora y Patología Vegetal del CEBAS-CSIC in Murcia (Spain), the University of St. Istvan (Budapest, Hungary) or by SharCo project (FP7-KBBE-2007-1) partners.

\subsection{WGS Mapping and PMC2 Screening}

WGSs of 73 cultivars were used in this study. Twenty-four of these WGSs and the 454 sequenced BAC clones belonging to the "Goldrich" PPVres locus R-haplotype were already screened in our previous works [20-31]. The other 49 WGSs were downloaded from the SRA repository (https://www. 
ncbi.nlm.nih.gov/sra). All raw reads were processed using the "run_trimmomatic_qual_trimming.pl" script from the Trinity software [32]. After removing the low-quality regions as well as vector and adaptor contaminants, cleaned reads were aligned to the peach genome v.2.0.a1 [33] using Bowtie2 v.2.2.4 software [34]. The presence/absence of the ParPMC2-del was visually inspected using IGV v.2.4.16 [35].

\section{Results and Discussion}

\subsection{High-Throughput DNA Extraction and ParPMC2-del Genotyping for MAS}

MAS offers great advantages over traditional seedling selection based just on phenotypic evaluations in fruit breeding [36]. DNA tests in segregating populations can improve the cost efficiency and/or the genetic gain for each seedling selection cycle [29], allowing to identify a few seedlings from among many thousands that have the genetic potential for desired performance levels [37]. As a result, agronomical evaluation in field trials is restricted to the promising selected materials. Implementation of MAS is especially valuable for traits that are difficult and/or expensive to phenotype as PPV resistance. As previously explained, the most reliable PPV resistance phenotyping is based on a biological test that uses graft-inoculated GF-305 peach seedlings [25] (Figure 1A). This protocol requires several replicates per genotype and visual symptoms inspection during $2-4$ growing seasons, which entails the main bottleneck in apricot breeding programs. For instance, following this method at the IVIA's greenhouse and cold chamber facilities, we can phenotype no more than 3000 plants per year, which equals 500 seedlings (i.e., 6 replicates are needed for each seedling).

In this work, we present a new strategy to speed up while reducing costs of the current application of MAS for PPV resistance in apricot $[18,24,28]$. Here, we combine a high-throughput DNA extraction protocol that does not need sophisticated robotic systems and can be implemented in any regular laboratory, with PMC2 allele-specific PCR amplification using previously described primers [21] and agarose electrophoresis (Figure 1B). Both forwards primers differ at the 3'-end, allowing to easily discriminate the presence/absence of the 5-bp ParPMC2-del (Figure 2). With this DNA extraction method, one person can easily process up to 384 samples (four 96-well sample plates) in 2 working days, enabling high throughput sample preparation. This is 4 times more samples than a standard CTAB method using individual tubes, while the cost of reagents and consumables is similar in both cases (around 0.29-0.30€ per sample) (Table S2). DNA obtained has enough quantity and quality to ensure subsequent regular PCRs. A 1:10 dilution of the DNA obtained was directly used for PCR amplification, without any additional purification step. In contrast, commercial kits are much more expensive in terms of reagents and consumables with costs around $4 €$ per sample. Then, using this DNA, 3 different methods could be applied for PPV MAS in apricot: the fluorescent labelling of PCR fragments that are resolved using capillary electrophoresis [18], the high-resolution melting (HRM) approach [28], and the use of standard PCR resolved by agarose gel electrophoresis [21]. It should be noted that the first two methods require the use of special equipment that could not be available for some laboratories and that also make the protocol more expensive. For instance, just the capillary electrophoresis costs around 1.5-2€ per sample (PCR not included) and the fluorescently labelled primers needed for PCR (136€10 nm) are much more expensive than the non-labelled ones ( $4 € 20 \mathrm{~nm})$. On the other hand, commercial kits for HRM are not very expensive (around $1 €$ per sample) but requires the use of real-time PCR machines specially calibrated for this type of experiments and the analysis software. As a resume, although prices differ between laboratories or countries, our rough estimate of the cost points to first and second approaches as 13 and 8 times more expensive, respectively, in terms of reagents and consumables than the protocol proposed in this work (Table S2).

Practical advantages of PMC2 genotyping over classical phenotyping may be illustrated by the following example (Figure 1). The estimated time needed for evaluating 1000 samples at the IVIA's facilities using bioassays is about 16 months (500 samples/8 months), taking into account that plants should be big enough to be ready-to-graft (approximately 2 years old). In contrast, just about 4 weeks 
are needed to conduct PMC2 genotyping just after seed germination. This estimated time was calculated assuming a 40-h workweek. As 1000 samples could be distributed into 10.496-well plates, ideally the DNA extraction would need 5.2 days (4 plates each 2 days), the 2 allele-specific PCRs would need 7.8 days ( $3 \mathrm{~h}$ each plate) and the agarose electrophoresis would last 2.6 days ( 2 PCR 96-well plates and $2 \mathrm{~h}$ per gel). In total, we would need 15.6 working days to genotype 1000 samples. This improvement removes the phenotyping bottleneck since all seedlings obtained from a particular cross can be PCR screened that same year. Hence, this quick and high-throughput method for DNA testing is expected to have an important effect on the cost efficiency of MAS, as suggested by Edge-Garza et al. [37].

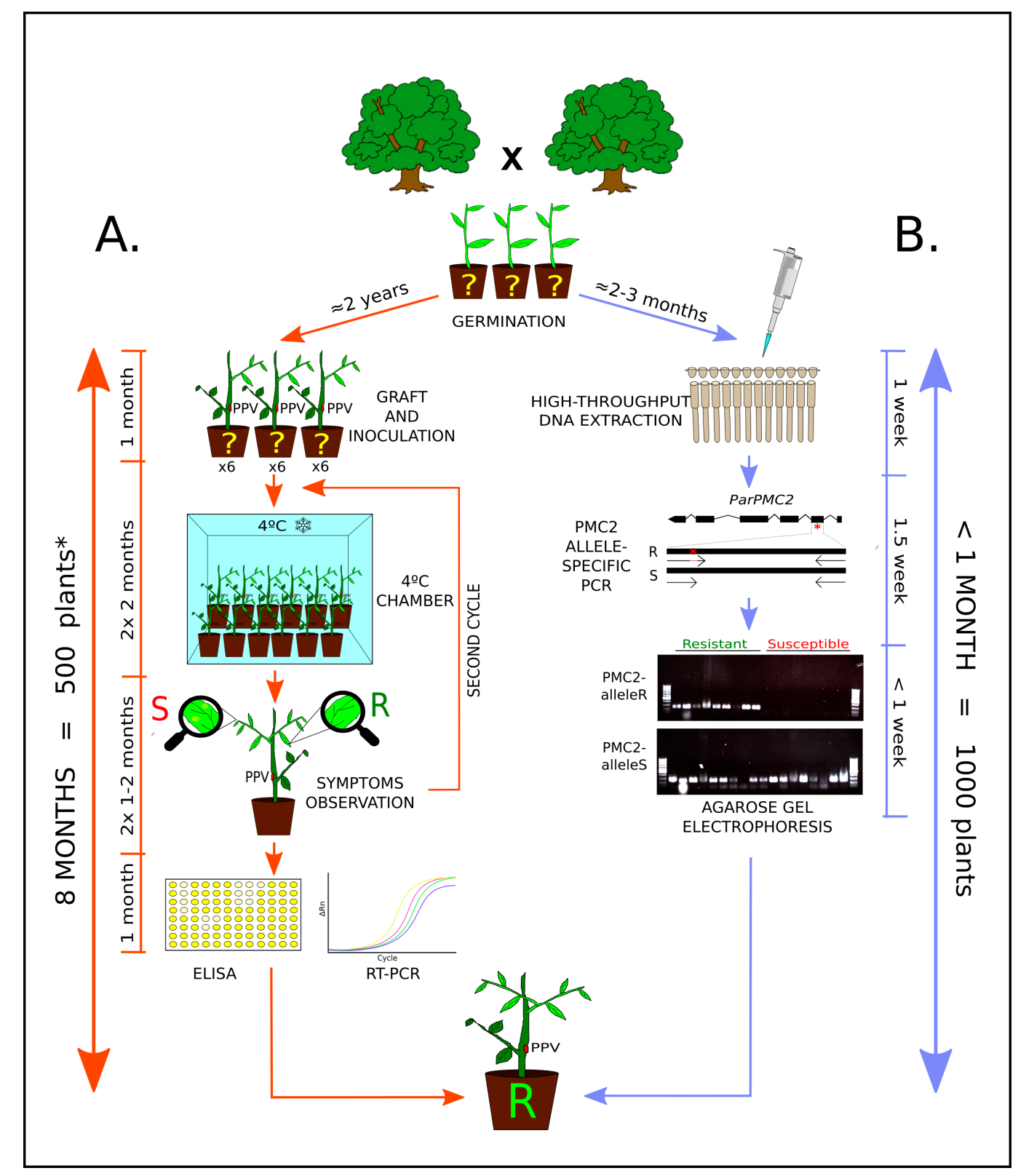

Figure 1. Comparison between traditional Plum pox virus (PPV) resistance phenotyping (A) and high-throughput marker-assisted selection (MAS) based on PMC2 allele-specific PCR (B). ${ }^{*}$ ) Estimated duration based on Instituto Valenciano de Investigaciones Agrarias (IVIA) facilities. 


\section{A}

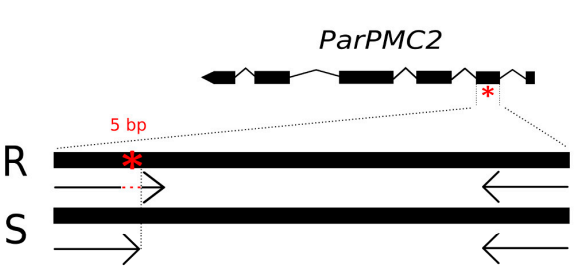

B

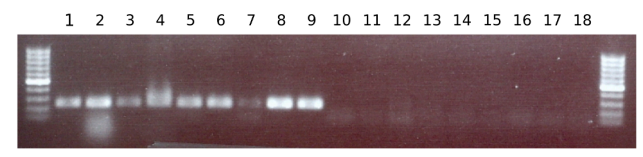

$1920 \quad 2122 \quad 23 \quad 24 \quad 2526 \quad 272829 \quad 30$

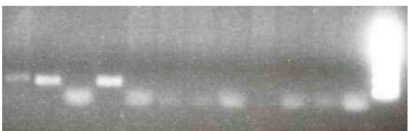

$31 \quad 32 \quad 33 \quad 34 \quad 35 \quad 36 \quad 3738 \quad 394041 \quad 42 \quad 4344 \quad 45 \quad 46$

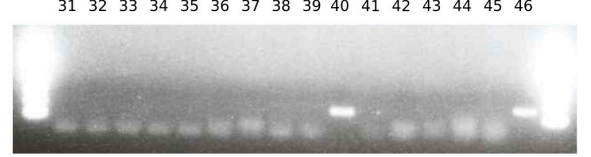

C s-allele

$\begin{array}{llllllllllllllllll}1 & 2 & 3 & 4 & 5 & 6 & 7 & 8 & 9 & 10 & 11 & 12 & 13 & 14 & 15 & 16 & 17 & 18\end{array}$

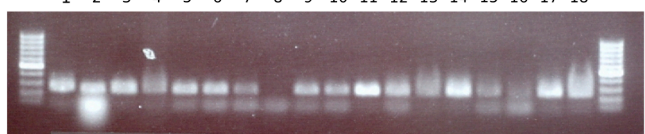

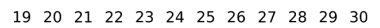

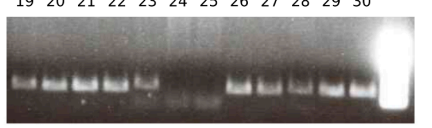

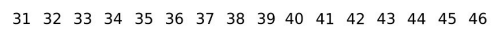

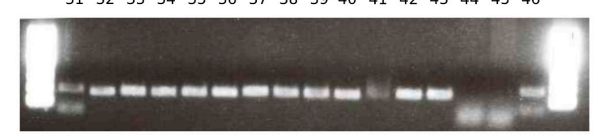

Figure 2. PMC2 genotyping by allele-specific PCR using forward primers differing at the 3 '-end (A): R-allele (B) and S-allele (C) amplifications in 1\% agarose gel electrophoresis for 46 apricot accessions (1: Goldrich, 2: Harlayne, 3: Henderson, 4: Lito, 5: Orange Red, 6: Pandora, 7: SEO, 8: Stella, 9: Veecot, 10: Bebeco, 11: Bergeron, 12: Canino, 13: Currot, 14: Ginesta, 15: Katy, 16: Mitger, 17: Palau, 18: Tyrinthos, 19: Piera, 20: Selene, 21: Colorao, 22: Moixent, 23: Perla, 24: Dama Vermella, 25: Maravilla, 26: Ninfa, 27: Palabras, 28: Sublime, 29: Dorada, 30: Castlebrite, 31: Martinet, 32: Corbató, 33: Gandía, 34: Cristalí, 35: Manri, 36: Gavatxet, 37: Pisana, 38: Xirivello, 39: Velazquez, 40: Mirlo Rojo, 41: Rojo Carlet, 42: Bulida, 43: ASP, 44: Silvercot, 45: Bora and 46: Roxana).

\subsection{ParPMC2-del Highly Correlates with PPV Resistance in Apricot Germplasm}

One of the main pillars of plant breeding relies on skilful parental selection to create new genetic variation by controlled crossing. Usually, breeders just connect the concept of DNA-informed breeding with the use of molecular markers for seedling selection, but it also can be very helpful for parental selection [36]. This is the case in apricot breeding for PPV resistance. Two decades ago, Martínez-Gómez et al. [9] reviewed phenotypic information regarding apricot cultivar behaviour against PPV. Similarly, here, we compile the PMC2 genotype of a wide set of apricot accessions to facilitate parental selection tasks incorporating also their resistance phenotype, pedigree and origin data from the literature when available. The PPV strain used for phenotyping was also included because differences in severity of the induced symptoms have been observed $[10,16]$. As a result, after screening 120 accessions by PCR and other 49 by WGS and reviewing the available literature, PMC2 genotype was determined in a total of 325 apricot cultivars or accessions that represent a wide range of geographic origins (Figure 3). A significant part of the materials come from European countries directly involved in PPV resistance research during the last decades, such as Italy (20.9\%), Spain (15.7\%) or France (14.8\%) [38-42]. Regarding viral strain, PPV-M was more frequently used for phenotyping except for PPV-D in Spain and PPV-T in Turkey (Figure 3), in agreement with the prevalence of these two strains in every country $[5,43]$. 


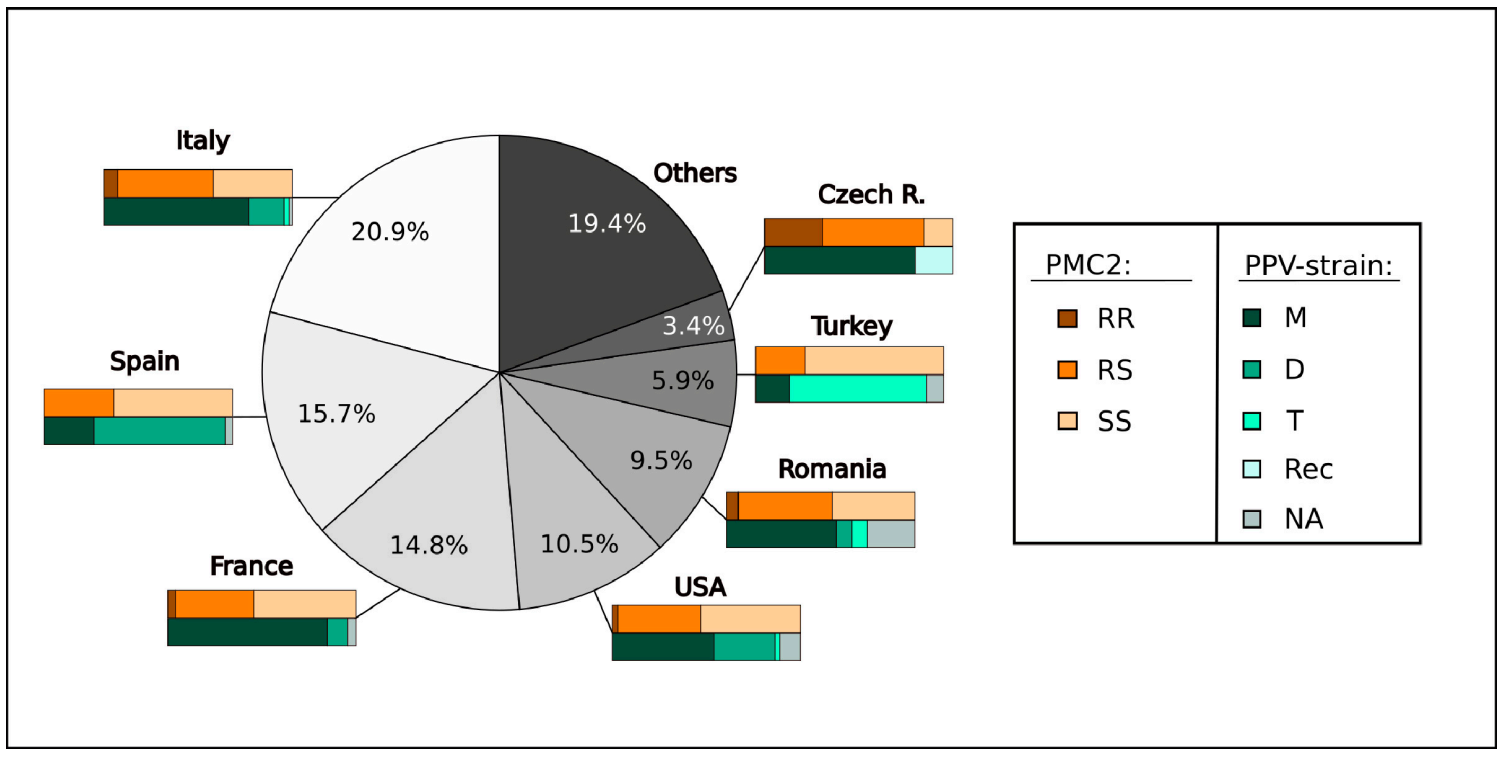

Figure 3. Geographic distribution of apricot accessions: PMC2 genotypes (RR: homozygous for the resistant allele; SS: homozygous for the susceptible allele; and RS: heterozygous) and PPV strain used for phenotyping are also indicated.

In total, 110 accessions were considered phenotypically resistant (Table 1), 108 were susceptible (Table 2) and 11 showed uncertain phenotype against the same or different PPV strains (Table 3). ParPMC2-del highly correlates with PPV resistance, as evidenced by its presence in $92.8 \%$ of the resistant accessions (Table 1) and its absence in $92.6 \%$ of the susceptible accessions (Table 2). Only 16 out of 219 (7.3\%) accessions phenotypically classified as resistant or susceptible showed genotype-phenotype incongruences (GPIs). GPIs were previously reported mainly when using segregating populations $[18,23,24,28,44]$, but clarifying reasons underlying GPIs was found difficult, as quite different factors may be involved. These factors include complex phenotyping protocols, loci other than PPVres contributing to PPV resistance, environmental conditions and/or gene-environment interactions. Additionally, putative misclassifications could also explain some genotypic discrepancies observed in this work. For instance, Sunglo, the resistant donor parent of Goldrich, has been phenotyped as resistant by several authors using PPV-M [15,45,46] and PPV-D [47] and genotypically showed the SSR-resistant alleles targeting the PPVres locus [18]. However, WGS data (SRR2153157) supposedly corresponding to this accession do not have the ParPMC2-del. Something similar occurs with Mirlo Naranja, classified as resistant [48], that was found to carry one copy of the ParPMC2-del by PCR in this work but not in that of Passaro [49]. Detailed accession documentation may be helpful to resolve these discrepancies, but 13 of the 16 identified GPIs have no pedigree data available. This information would be very valuable to increase the efficiency of apricot breeding programs and germplasm management. 
Table 1. Apricot PPV-resistant accessions genotyped for PMC2.

\begin{tabular}{|c|c|c|c|c|c|c|c|c|}
\hline Name & Country $^{a}$ & Origin & Pedigree & $\begin{array}{l}\text { PPV Resistance } \\
\text { Phenotype }{ }^{b}\end{array}$ & $\begin{array}{l}\text { PPV Strain } \\
\text { Used }\end{array}$ & $\begin{array}{c}\text { First Phenotype } \\
\text { Ref }\end{array}$ & $\begin{array}{c}\text { PMC2 } \\
\text { Genotype }\end{array}$ & $\begin{array}{c}\text { PMC2 } \\
\text { Genotype Ref }\end{array}$ \\
\hline A4316 & IT & & & $\mathrm{R}$ & $\mathrm{M}$ & [15] & RS & WGS \\
\hline A4804 & IT & & & $\mathrm{R}$ & M & [15] & RS & WGS \\
\hline \multirow{2}{*}{ Adriana (= Le-3241) } & \multirow{2}{*}{$\mathrm{CR}$} & \multirow{2}{*}{$\begin{array}{l}\text { Horticulture Faculty, } \\
\text { Lednice }\end{array}$} & \multirow{2}{*}{ Vestar $\times$ SEO $[50]$} & \multirow{2}{*}{$\mathrm{R}$} & $\mathrm{M}$ & [51] & \multirow{2}{*}{$\mathrm{RR}$} & \multirow{2}{*}{ [24] } \\
\hline & & & & & $\operatorname{Rec}$ & [52] & & \\
\hline Alfred (= NY345) & USA & $\begin{array}{l}\text { Geneva, NY State Expt } \\
\text { Sta, by Robert C. Lamb }\end{array}$ & $\begin{array}{l}\text { OP seedling of selection } \\
\text { from (Doty } \times \text { Geneva) }\end{array}$ & $\mathrm{R}$ & M & [53] & RS & WGS \\
\hline Andswee & IR & & & $\mathrm{R}$ & $\mathrm{M}$ & [15] & RS & WGS \\
\hline Anegat & FR & INRA, CEP Innovation & & $\mathrm{R}$ & $\mathrm{M} / \mathrm{D}$ & [54] & RS & [49] \\
\hline \multirow{2}{*}{ Bergarouge (= Avirine A2914) } & \multirow{2}{*}{ FR } & \multirow{2}{*}{ INRA } & \multirow{2}{*}{ Bergeron $\times$ Orange Red [55] } & \multirow{2}{*}{$\mathrm{R}$} & $\mathrm{D}$ & [23] & \multirow{2}{*}{ RS } & \multirow{2}{*}{ [49] } \\
\hline & & & & & $\mathrm{M}$ & [56] & & \\
\hline Bergeval (= Aviclo, A3950) & FR & INRA & & $\mathrm{R}$ & $\mathrm{M}$ & [56] & RS & [49] \\
\hline BO03615011 & IT & & Goldrich $\times$ Harlayne [28] & $\mathrm{R}$ & $\mathrm{M}^{*}$ & [49] & RS & [49] \\
\hline BO03615025 & IT & & Goldrich $\times$ Harlayne [28] & $\mathrm{R}$ & $\mathrm{M}^{*}$ & [49] & $\mathrm{RR}$ & [49] \\
\hline BO03615034 & IT & & Goldrich $\times$ Harlayne [28] & $\mathrm{R}$ & $\mathrm{M}^{*}$ & [28] & $\mathrm{RR}$ & [28] \\
\hline BO03615049 & IT & & Goldrich $\times$ Harlayne [28] & $\mathrm{R}$ & $\mathrm{M}^{*}$ & [28] & $\mathrm{RR}$ & [28] \\
\hline BO03615053 & IT & & Goldrich $\times$ Harlayne [28] & $\mathrm{R}$ & $\mathrm{M}^{*}$ & [28] & RS & [28] \\
\hline BO03615070 & IT & & Goldrich $\times$ Harlayne [28] & $\mathrm{R}$ & $\mathrm{M}^{*}$ & [49] & $\mathrm{RR}$ & [49] \\
\hline BO04624031 & IT & & Portici $\times$ Goldrich [28] & $\mathrm{R}$ & $\mathrm{M}^{*}$ & [28] & RS & [28] \\
\hline BO04624039 & IT & & Portici $\times$ Goldrich [28] & $\mathrm{R}$ & $\mathrm{M}^{*}$ & [49] & SS & [49] \\
\hline BO05636034 & IT & & Kyoto $\times$ Priscilla [28] & $\mathrm{R}$ & $\mathrm{M}^{*}$ & {$[28]$} & RS & {$[28]$} \\
\hline BO06609012 & IT & & Silvercot $\times$ Bora $[28]$ & $\mathrm{R}$ & $\mathrm{M}^{*}$ & [49] & RS & [49] \\
\hline BO06609013 & IT & & Silvercot $\times$ Bora [28] & $\mathrm{R}$ & $\mathrm{M}^{*}$ & [49] & RS & [49] \\
\hline BO06609024 & IT & & Silvercot $\times$ Bora $[28]$ & $\mathrm{R}$ & $\mathrm{M}^{*}$ & [49] & RS & [49] \\
\hline BO06609033 & IT & & Silvercot $\times$ Bora $[28]$ & $\mathrm{R}$ & $\mathrm{M}^{*}$ & [49] & RS & [49] \\
\hline BO06609036 & IT & & Silvercot $\times$ Bora $[28]$ & $\mathrm{R}$ & $\mathrm{M}^{*}$ & [49] & RS & [49] \\
\hline BO06609037 & IT & & Silvercot $\times$ Bora $[28]$ & $\mathrm{R}$ & $\mathrm{M}^{*}$ & [49] & RS & [49] \\
\hline BO06609039 & IT & & Silvercot $\times$ Bora $[28]$ & $\mathrm{R}$ & $\mathrm{M}^{*}$ & [49] & RS & [49] \\
\hline BO06609045 & IT & & Silvercot $\times$ Bora [28] & $\mathrm{R}$ & $M^{*}$ & [49] & RS & [49] \\
\hline
\end{tabular}


Table 1. Cont.

\begin{tabular}{|c|c|c|c|c|c|c|c|c|}
\hline Name & Country ${ }^{a}$ & Origin & Pedigree & $\begin{array}{l}\text { PPV Resistance } \\
\text { Phenotype }^{b}\end{array}$ & $\begin{array}{l}\text { PPV Strain } \\
\text { Used }\end{array}$ & $\begin{array}{c}\text { First Phenotype } \\
\text { Ref }\end{array}$ & $\begin{array}{c}\text { PMC2 } \\
\text { Genotype }\end{array}$ & $\begin{array}{c}\text { PMC2 } \\
\text { Genotype Ref }\end{array}$ \\
\hline BO06609048 & IT & & Silvercot $\times$ Bora [28] & $\mathrm{R}$ & $\mathrm{M}^{*}$ & [28] & RS & [28] \\
\hline BO06609055 & IT & & Silvercot $\times$ Bora [28] & $\mathrm{R}$ & $\mathrm{M}^{*}$ & [28] & RS & [28] \\
\hline BO06609060 & IT & & Silvercot $\times$ Bora [28] & $\mathrm{R}$ & $\mathrm{M}^{*}$ & [49] & RS & [49] \\
\hline BO06609068 & IT & & Silvercot $\times$ Bora $[28]$ & $\mathrm{R}$ & $\mathrm{M}^{*}$ & [49] & RS & [49] \\
\hline BO06609074 & IT & & Silvercot $\times$ Bora [28] & $\mathrm{R}$ & $\mathrm{M}^{*}$ & [49] & RS & [49] \\
\hline BO06609079 & IT & & Silvercot $\times$ Bora $[28]$ & $\mathrm{R}$ & $\mathrm{M}^{*}$ & [49] & RS & [49] \\
\hline BO06609083 & IT & & Silvercot $\times$ Bora $[28]$ & $\mathrm{R}$ & $\mathrm{M}^{*}$ & [49] & RS & [49] \\
\hline BO06609087 & IT & & Silvercot $\times$ Bora $[28]$ & $\mathrm{R}$ & $\mathrm{M}^{*}$ & [49] & RS & [49] \\
\hline BO06609099 & IT & & Silvercot $\times$ Bora $[28]$ & $\mathrm{R}$ & $\mathrm{M}^{*}$ & [49] & RS & [49] \\
\hline BO06609104 & IT & & Silvercot $\times$ Bora $[28]$ & $\mathrm{R}$ & $\mathrm{M}^{*}$ & [49] & RS & [49] \\
\hline BO06609113 & IT & & Silvercot $\times$ Bora [28] & $\mathrm{R}$ & $\mathrm{M}^{*}$ & [49] & RS & [49] \\
\hline BO06609129 & IT & & Silvercot $\times$ Bora $[28]$ & $\mathrm{R}$ & $\mathrm{M}^{*}$ & [49] & RS & [49] \\
\hline BO06609133 & IT & & Silvercot $\times$ Bora $[28]$ & $\mathrm{R}$ & $\mathrm{M}^{*}$ & [49] & RS & [49] \\
\hline BO06609136 & IT & & Silvercot $\times$ Bora $[28]$ & $\mathrm{R}$ & $\mathrm{M}^{*}$ & [49] & RS & [49] \\
\hline BO96621002 & IT & & Goldrich $\times$ Lito [28] & $\mathrm{R}$ & $\mathrm{M}$ & [57] & RR & [28] \\
\hline BO96621030 & IT & & Goldrich $\times$ Lito [28] & $\mathrm{R}$ & $\mathrm{M}$ & [57] & RS & [28] \\
\hline Bora (BO90610010) & IT & $\begin{array}{l}\text { University of Bologna } \\
\text { and Milan, by D. Bassi }\end{array}$ & Early Blush $\times$ PA 7005-2 [58] & $\mathrm{R}$ & $\mathrm{M} / \mathrm{D}$ & [58] & RS & {$[21,28]$} \\
\hline Candela (= LE-2927) & $\mathrm{CR}$ & $\begin{array}{l}\text { Horticulture Faculty, } \\
\text { Lednice }\end{array}$ & Hungarian Best $\times$ SEO [59] & $\mathrm{R}$ & M & [60] & RR & [49] \\
\hline Cebir & TU & & & $\mathrm{R}$ & $\mathrm{T}$ & [61] & RS & [61] \\
\hline Congat & FR & INRA, CEP Innovation & & $\mathrm{R}$ & - & {$[62]$} & RS & [49] \\
\hline \multirow{3}{*}{$\begin{array}{c}\text { Early Blush (= RUTBHART, } \\
\text { NJA53, Aurora46) }\end{array}$} & \multirow{3}{*}{ US } & \multirow{3}{*}{$\begin{array}{c}\text { Rutgers Horticultural } \\
\text { Research Farm, New } \\
\text { Brunswick, N.J. }\end{array}$} & \multirow{3}{*}{ RR17-62 × NJA-13 [63] } & \multirow{3}{*}{$\mathrm{R}$} & $\mathrm{D}$ & [64] & \multirow{3}{*}{ RS } & \multirow{3}{*}{ PCR; $[21,28,61]$} \\
\hline & & & & & $\mathrm{M}$ & [65] & & \\
\hline & & & & & $\mathrm{T}$ & [61] & & \\
\hline Farlis & FR & $\begin{array}{l}\text { Marie-France BOIS, } \\
\text { France (IPS) }\end{array}$ & & $\mathrm{R}$ & $\mathrm{M}^{*}$ & {$[28,49]$} & RS & {$[28]$} \\
\hline Farmingdale (=NY346) & USA & $\begin{array}{l}\text { Geneva, NY State Expt } \\
\text { Sta, by Robert C. Lamb }\end{array}$ & $\begin{array}{l}\text { OP seedling of selection } \\
\text { from (Doty } \times \text { Geneva) }[66]\end{array}$ & $\mathrm{R}$ & M & [53] & RS & [28] \\
\hline
\end{tabular}


Table 1. Cont.

\begin{tabular}{|c|c|c|c|c|c|c|c|c|}
\hline Name & Country $^{a}$ & Origin & Pedigree & $\begin{array}{l}\text { PPV Resistance } \\
\text { Phenotype }\end{array}$ & $\begin{array}{l}\text { PPV Strain } \\
\text { Used }\end{array}$ & $\begin{array}{c}\text { First Phenotype } \\
\text { Ref }\end{array}$ & $\begin{array}{c}\text { PMC2 } \\
\text { Genotype }\end{array}$ & $\begin{array}{c}\text { PMC2 } \\
\text { Genotype Ref }\end{array}$ \\
\hline Flavor cot (=Bayoto) & USA & $\begin{array}{c}\text { Washington State } \\
\text { University Research, by } \\
\text { Tom Toyama }\end{array}$ & & $\mathrm{R}$ & M & [57] & RS & [28] \\
\hline Flopria & FR & $\begin{array}{l}\text { PSB Producción Vegetal } \\
\text { S.L. }\end{array}$ & & $\mathrm{R}$ & $\mathrm{M}^{*}$ & [28] & RS & PCR; [28] \\
\hline GG9310 & SP & IVIA, Moncada, Valencia & Goldrich $\times$ Ginesta [18] & $\mathrm{R}$ & $\mathrm{D}$ & IVIA & RS & PCR \\
\hline GG9318 & SP & IVIA, Moncada, Valencia & Goldrich $\times$ Ginesta [18] & $\mathrm{R}$ & $\mathrm{D}$ & IVIA & RS & PCR \\
\hline GG937 & $\mathrm{SP}$ & IVIA, Moncada, Valencia & Goldrich $\times$ Ginesta [18] & $\mathrm{R}$ & $\mathrm{D}$ & IVIA & RS & PCR \\
\hline GG941 & SP & IVIA, Moncada, Valencia & Goldrich $\times$ Ginesta [18] & $\mathrm{R}$ & $\mathrm{D}$ & IVIA & RS & PCR \\
\hline GG979 & SP & IVIA, Moncada, Valencia & Goldrich $\times$ Ginesta [18] & $\mathrm{R}$ & $\mathrm{D}$ & IVIA & RS & PCR \\
\hline GG9869 & SP & IVIA, Moncada, Valencia & Goldrich $\times$ Ginesta [18] & $\mathrm{R}$ & $\mathrm{D}$ & IVIA & RS & PCR \\
\hline Gilgat & FR & $\begin{array}{l}\text { INRA / CEP } \\
\text { INNOVATION }\end{array}$ & & $\mathrm{R}$ & $\mathrm{M}^{*}$ & [28]; [49] & RS & {$[28]$} \\
\hline GP9817 & SP & IVIA, Moncada, Valencia & Goldrich $\times$ Palau [18] & $\mathrm{R}$ & $\mathrm{D}$ & IVIA & RS & PCR \\
\hline Dama Rosa (GG9871) & SP & IVIA, Moncada, Valencia & Goldrich $\times$ Ginesta [18] & $\mathrm{R}$ & $\mathrm{D}$ & IVIA & RS & PCR; [49] \\
\hline Dama Taronja (GK988) & SP & IVIA, Moncada, Valencia & Goldrich $\times$ Katy [18] & $\mathrm{R}$ & $\mathrm{D}$ & IVIA & RS & PCR; [49] \\
\hline Dulcinea & IT & Pisa University & Moniqui OP [67] & $\mathrm{R}$ & $\mathrm{D}$ & [64] & SS & PCR; [49] \\
\hline Fracasso & IT & & & Tolerant & $\mathrm{T}$ & [61] & SS & [61] \\
\hline \multirow{2}{*}{ Harlayne } & \multirow{2}{*}{ C } & \multirow{2}{*}{$\begin{array}{c}\text { Agr. Canada, Res. } \\
\text { Station, Harrow, Ontario, } \\
\text { by REC Layne }\end{array}$} & \multirow{2}{*}{$\begin{array}{c}\text { V51092 }((\text { Reliable } \times \text { OP }) \times \\
\text { OP }) \times \text { Sun Glo [66] }\end{array}$} & \multirow{2}{*}{$\mathrm{R}$} & $\mathrm{D}$ & [68] & \multirow{2}{*}{ RS } & \multirow{2}{*}{$\begin{array}{c}\text { PCR; } \\
{[20,21,24,28,61]}\end{array}$} \\
\hline & & & & & $\mathrm{M}$ & [45] & & \\
\hline Harval (=HW437) & C & $\begin{array}{l}\text { Agr. Canada, Res. } \\
\text { Station, Harrow, Ontario, } \\
\text { by REC Layne }\end{array}$ & $\begin{array}{l}\text { Veecot } \times \text { HW435 (Rouge du } \\
\text { Roussillon } \times \text { NJA2 } \\
(\text { Morden604 OP)) [66] }\end{array}$ & $\mathrm{R}$ & M & [69] & RS & [28] \\
\hline \multirow{2}{*}{ Henderson } & \multirow{2}{*}{ USA } & \multirow{2}{*}{$\begin{array}{l}\text { Geneva, NY, by GW } \\
\text { Henderson }\end{array}$} & \multirow{2}{*}{ Unknown [66] } & \multirow{2}{*}{$\mathrm{R}$} & $\mathrm{M}$ & [46] & \multirow{2}{*}{ RS } & \multirow{2}{*}{ PCR; [21] } \\
\hline & & & & & $\mathrm{D}$ & [70] & & \\
\hline Kaniş (=M2252) & $\mathrm{TU}$ & & & $\mathrm{R}$ & $\mathrm{T}$ & [61] & SS & [61] \\
\hline Karum & $\mathrm{TU}$ & & & $\mathrm{R}$ & $\mathrm{T}$ & [61] & RS & [61] \\
\hline Lady cot (=HYB 3-3) & FR & COT International & & $\mathrm{R}$ & $\mathrm{M}^{*}$ & [28] & RS & [28] \\
\hline Laycot & C & & $\begin{array}{c}\text { V51092 ((Reliable o.p.) o.p.) } \\
\text { × NJA1 [71] }\end{array}$ & $\mathrm{R}$ & M & [15] & $\mathrm{RR}$ & WGS \\
\hline
\end{tabular}


Table 1. Cont

\begin{tabular}{|c|c|c|c|c|c|c|c|c|}
\hline Name & Country ${ }^{a}$ & Origin & Pedigree & $\begin{array}{l}\text { PPV Resistance } \\
\text { Phenotype }{ }^{b}\end{array}$ & $\begin{array}{l}\text { PPV Strain } \\
\text { Used }\end{array}$ & $\begin{array}{c}\text { First Phenotype } \\
\text { Ref }\end{array}$ & $\begin{array}{c}\text { PMC2 } \\
\text { Genotype }\end{array}$ & $\begin{array}{c}\text { PMC2 } \\
\text { Genotype Ref }\end{array}$ \\
\hline LE-2904 & CR & $\begin{array}{l}\text { Horticulture Faculty, } \\
\text { Lednice }\end{array}$ & Velkopavlovická × SEO [19] & $\mathrm{R}$ & $\mathrm{M}$ & [72] & RS & [49] \\
\hline LE-3205 & CR & $\begin{array}{l}\text { Horticulture Faculty, } \\
\text { Lednice }\end{array}$ & & $\mathrm{R}$ & $\mathrm{M}^{*}$ & [49] & $\mathrm{RR}$ & [49] \\
\hline Le-3246 & $\mathrm{CR}$ & $\begin{array}{l}\text { Horticulture Faculty, } \\
\text { Lednice }\end{array}$ & Vestar $\times$ SEO [51] & $\mathrm{R}$ & M & [51] & RS & [24] \\
\hline LE-3662 & $\mathrm{CR}$ & $\begin{array}{l}\text { Horticulture Faculty, } \\
\text { Lednice }\end{array}$ & & $\mathrm{R}$ & M & [72] & $\mathrm{RR}$ & [49] \\
\hline Lifos & $\mathrm{TU}$ & & & $\mathrm{R}$ & $\mathrm{T}$ & [61] & RS & [61] \\
\hline Lillycot & FR & SDR Fruit Llc (US) & Unknown [73] & $\mathrm{R}$ & $\mathrm{M}^{*}$ & {$[28]$} & RS & {$[28]$} \\
\hline \multirow{2}{*}{ Lito } & \multirow{2}{*}{ GR } & & \multirow{2}{*}{ SEO $\times$ Tirynthos [18] } & \multirow{2}{*}{$\mathrm{R}$} & $\mathrm{M}$ & [74] & \multirow{2}{*}{ RS } & \multirow{2}{*}{ PCR; $[24,28]$} \\
\hline & & & & & $\mathrm{D}$ & IVIA & & \\
\hline Mediabel (=Mediabell) & FR & Newcot and IPS & & $\mathrm{R}$ & $\mathrm{M}^{*}$ & [28] & RS & {$[28]$} \\
\hline \multirow{2}{*}{$\begin{array}{c}\text { Mirlo Naranja (= Mirlo } \\
\text { anaranjado) }\end{array}$} & \multirow{2}{*}{ SP } & \multirow{2}{*}{ CEBAS-CSIC, Murcia } & \multirow{2}{*}{$\begin{array}{c}\text { Rojo Pasión } \times \text { Búlida Precoz } \\
{[48]}\end{array}$} & \multirow{2}{*}{$\mathrm{R}$} & \multirow{2}{*}{$\mathrm{D}$} & \multirow{2}{*}{ [48] } & RS & PCR \\
\hline & & & & & & & SS & [49] \\
\hline Mirlo Blanco & SP & CEBAS-CSIC, Murcia & $\begin{array}{c}\text { Rojo Pasión } \times \text { Búlida Precoz } \\
{[48]}\end{array}$ & $\mathrm{R}$ & $\mathrm{D}$ & [48] & RS & [28] \\
\hline Mirlo Rojo & SP & CEBAS-CSIC, Murcia & $\begin{array}{c}\text { Rojo Pasión } \times \text { Búlida Precoz } \\
{[48]}\end{array}$ & $\mathrm{R}$ & $\mathrm{D}$ & [48] & RS & PCR; [49] \\
\hline Mogador & SP & $\begin{array}{c}\text { PSB Producción Vegetal } \\
\text { S.L. }\end{array}$ & & $\mathrm{R}$ & $\mathrm{M}^{*}$ & {$[28,49]$} & RS & PCR; [28] \\
\hline Moixent (=GM961) & SP & IVIA, Valencia & Goldrich $\times$ Mitger [18] & $\mathrm{R}$ & $\mathrm{D}$ & IVIA & RS & PCR; [49] \\
\hline \multirow{2}{*}{ Murciana } & \multirow{2}{*}{ SP } & \multirow{2}{*}{ CEBAS-CSIC, Murcia } & \multirow{2}{*}{ Orange Red × Currot [73] } & \multirow{2}{*}{$\mathrm{R}$} & $\mathrm{D}$ & [75] & \multirow{2}{*}{ RS } & \multirow{2}{*}{ WGS; PCR; [49] } \\
\hline & & & & & $\mathrm{M}$ & [15] & & \\
\hline Nikitskii & UKR & & & $\mathrm{R}$ & $\mathrm{M}$ & [15] & RS & WGS \\
\hline NJA42 & USA & New Jersey & NJA12 × NJA13 [76] & $\mathrm{R}$ & $?$ & [77] & RS & PCR \\
\hline \multirow{2}{*}{ Orange Red (=Barth; NJA-32) } & \multirow{2}{*}{ USA } & \multirow{2}{*}{ New Jersey } & \multirow{2}{*}{$\begin{array}{c}\text { Lasgerdi Mashhad } \times \text { NJA2 } \\
(=\text { Morden } 604 \text { OP) [78] }\end{array}$} & \multirow{2}{*}{$\mathrm{R}$} & $\mathrm{D}$ & {$[68]$} & \multirow{2}{*}{ RS } & \multirow{2}{*}{ PCR; [21] } \\
\hline & & & & & $\mathrm{M}$ & [79] & & \\
\hline \multirow{2}{*}{ Pandora } & \multirow{2}{*}{ GR } & & \multirow{2}{*}{ SEO $\times$ Tirynthos [18] } & \multirow{2}{*}{$\mathrm{R}$} & $\mathrm{M}$ & [74] & \multirow{2}{*}{ RS } & \multirow{2}{*}{ PCR } \\
\hline & & & & & $\mathrm{D}$ & [47] & & \\
\hline
\end{tabular}


Table 1. Cont

\begin{tabular}{|c|c|c|c|c|c|c|c|c|}
\hline Name & Country ${ }^{a}$ & Origin & Pedigree & $\begin{array}{l}\text { PPV Resistance } \\
\text { Phenotype }^{b}\end{array}$ & $\begin{array}{l}\text { PPV Strain } \\
\text { Used }\end{array}$ & $\begin{array}{c}\text { First Phenotype } \\
\text { Ref }\end{array}$ & $\begin{array}{c}\text { PMC2 } \\
\text { Genotype }^{c}\end{array}$ & $\begin{array}{c}\text { PMC2 } \\
\text { Genotype Ref }\end{array}$ \\
\hline Pelese di Giovanniello & IT & & & Tolerant & $\mathrm{D}$ & [64] & SS & [49] \\
\hline Perla & $\mathrm{SP}$ & Murcia & & $\mathrm{R}$ & $\mathrm{D}$ & [64] & SS & PCR \\
\hline Petra (BO88617102) & IT & $\begin{array}{l}\text { University of Bologna } \\
\text { and Milan, Italy, by D } \\
\text { Bassi }\end{array}$ & $\begin{array}{l}\text { Goldrich } \times \text { Pelese di } \\
\text { Giovanniello [73] }\end{array}$ & $\mathrm{R}$ & $\mathrm{M}^{*}$ & [28] & RS & [28] \\
\hline Precoce d'Imola & IT & & & tolerant & $\mathrm{D}$ & [64] & SS & WGS \\
\hline Priboto (=Zebra) & FR & & $\begin{array}{l}\text { bud mutation of Goldrich } \\
\text { [80] }\end{array}$ & $\mathrm{R}$ & M & [15] & RS & WGS; [49] \\
\hline Pricia & FR & $\begin{array}{l}\text { Marie-France BOIS, } \\
\text { France (IPS) }\end{array}$ & & $\mathrm{R}$ & $\mathrm{M}^{*}$ & {$[28,49]$} & RS & [28] \\
\hline Pseudo Royal & USA & & & $\mathrm{R}$ & M & [15] & RS & WGS \\
\hline Robada (= K106-2) & USA & Parlier, California & $\begin{array}{l}\text { Orange Red } \times \text { K113-40 } \\
\text { (ancestry includes Blenheim, } \\
\text { Blush and Perfection) [81] }\end{array}$ & $\mathrm{R}$ & M & [82] & RS & WGS \\
\hline Rojo Pasión & SP & CEBAS-CSIC & Orange Red $\times$ Currot [83] & $\mathrm{R}$ & $\mathrm{D}$ & [83] & RS & PCR; [49] \\
\hline \multirow{2}{*}{ Rosa } & \multirow{2}{*}{ SP } & \multirow{2}{*}{ CEBAS-CSIC, Murcia } & \multirow{2}{*}{ Orange Red $\times$ Palsteyn [73] } & $\mathrm{R}$ & \multirow{2}{*}{$\mathrm{D}$} & [41] & \multirow{2}{*}{ RS } & \multirow{2}{*}{ [49] } \\
\hline & & & & Tolerant & & [23] & & \\
\hline Rubista & FR & $\begin{array}{l}\text { Marie-France BOIS, } \\
\text { France (IPS) }\end{array}$ & & $\mathrm{R}$ & $\mathrm{M}^{*}$ & {$[28,49]$} & RS & [28] \\
\hline $\begin{array}{l}\text { Sabbatani (= Selezione } \\
\text { Sabbatani?) }\end{array}$ & IT & & & $\mathrm{R}$ & $\mathrm{D}$ & [64] & SS & [49] \\
\hline Selene & SP & CEBAS-CSIC & $\begin{array}{c}\text { Goldrich } \times \text { A2564 (=Screara } \\
\times \text { SEO) [18] }\end{array}$ & $\mathrm{R}$ & $\mathrm{D}$ & [84] & RS & PCR; [49] \\
\hline SEOP934 & SP & IVIA & SEO $\times$ Palau [18] & $\mathrm{R}$ & $\mathrm{D}$ & IVIA & RS & PCR \\
\hline Spring Blush (= EA3126TH) & FR & Escande EARL & & $\mathrm{R}$ & $\mathrm{M}^{*}$ & [57] & $R R$ & [49] \\
\hline \multirow{2}{*}{$\begin{array}{l}\text { Stark Early Orange (= SEO, } \\
\text { Earle Orange) }\end{array}$} & \multirow{2}{*}{ USA } & \multirow{2}{*}{$\begin{array}{c}\text { Grandview, Washington, } \\
\text { by WL Roberts }\end{array}$} & \multirow{2}{*}{ Unknown [66] } & \multirow{2}{*}{$\mathrm{R}$} & $\mathrm{M}$ & [85] & \multirow{2}{*}{ RS } & \multirow{2}{*}{$\begin{array}{c}\text { PCR; } \\
{[20,21,24,28,61]}\end{array}$} \\
\hline & & & & & $\mathrm{D}$ & [70] & & \\
\hline \multirow{2}{*}{ Stella } & \multirow{2}{*}{ USA } & & \multirow{2}{*}{ Unknown [18] } & \multirow{2}{*}{$\mathrm{R}$} & $\mathrm{M}$ & [85] & \multirow{2}{*}{ RR } & \multirow{2}{*}{ PCR; [21] } \\
\hline & & & & & $\mathrm{D}$ & [70] & & \\
\hline \multirow{2}{*}{ Sunglo (= Sun Glo) } & \multirow{2}{*}{ USA } & \multirow{2}{*}{$\begin{array}{c}\text { Columbia \& Okanogan } \\
\text { Nursery Co. }\end{array}$} & \multirow{2}{*}{ Unknown [66] } & \multirow{2}{*}{$\mathrm{R}$} & $\mathrm{M}$ & [45] & RS & PCR \\
\hline & & & & & D & [47] & SS & WGS \\
\hline
\end{tabular}


Table 1. Cont.

\begin{tabular}{|c|c|c|c|c|c|c|c|c|}
\hline Name & Country $^{a}$ & Origin & Pedigree & $\begin{array}{l}\text { PPV Resistance } \\
\text { Phenotype }^{b}\end{array}$ & $\begin{array}{l}\text { PPV Strain } \\
\text { Used }\end{array}$ & $\begin{array}{c}\text { First Phenotype } \\
\text { Ref }\end{array}$ & $\begin{array}{c}\text { PMC2 } \\
\text { Genotype }^{c}\end{array}$ & $\begin{array}{c}\text { PMC2 } \\
\text { Genotype Ref }\end{array}$ \\
\hline Sunnycot (= 97-3-203) & USA & SDR FRUIT LLC - USA & & $\mathrm{R}$ & & [62] & RS & [49] \\
\hline Traian & $\mathrm{RO}$ & & & $\mathrm{R}$ & $\mathrm{D}$ & [86] & RS & PCR; [87] \\
\hline Tsunami (= EA 5016) & FR & Escande EARL & & $\mathrm{R}$ & $\mathrm{M}^{*}$ & {$[28]$} & RS & {$[28]$} \\
\hline Wonder Cot (= RM 7) & USA & SDR FRUIT LLC - USA & & $\mathrm{R}$ & $\mathrm{M}^{*}$ & {$[28]$} & RS & {$[28]$} \\
\hline Zard & CA & & & $\mathrm{R}$ & $\mathrm{T}$ & [61] & RS & [61] \\
\hline
\end{tabular}

$\mathrm{M}^{*}$ : strain likely used for phenotyping by the Phytosanitary Service, Emilia-Romagna (Italy). ${ }^{a}$ Countries: C: Canada, CA: Central Asia, CR: Czech Republic, FR: France, GR: Greece, IR: Iran, IT: Italy, RO: Romania, SP: Spain, TU: Tunisia, TR: Turkey, UKR: Ukraine, US: United States of America; ${ }^{b}$ Phenotype: R: Resistant, S: Susceptible; ${ }^{c}$ Genotype: RR: homozygous for PMC2 resistant allele, SS: homozygous for PMC2 susceptible allele, RS: heterozygous.

Table 2. Apricot PPV susceptible accessions genotyped for ParPMC2-del.

\begin{tabular}{|c|c|c|c|c|c|c|c|c|}
\hline Cultivar & Country $^{a}$ & Origin & Pedigree & $\begin{array}{l}\text { PPV Resistance } \\
\text { Phenotype }^{\mathbf{b}}\end{array}$ & $\begin{array}{c}\text { PPV Strain } \\
\text { Used }\end{array}$ & $\begin{array}{c}\text { First } \\
\text { Phenotype Ref }\end{array}$ & $\begin{array}{c}\text { PMC2 } \\
\text { Genotype }^{c}\end{array}$ & $\begin{array}{c}\text { PMC2 } \\
\text { Genotype Ref }\end{array}$ \\
\hline A3521 & IR & & & $\mathrm{S}$ & $\mathrm{M}$ & [15] & SS & WGS \\
\hline A3522 & IR & & & $\mathrm{S}$ & $\mathrm{M}$ & [15] & SS & WGS \\
\hline Amabile Vecchoni & IT & Seedling by Prof. F. Scaramuzzi & Unknown [67] & $\mathrm{S}$ & $\mathrm{M}$ & [45] & SS & [49] \\
\hline Aprikoz & TR & & & $\mathrm{S}$ & $\mathrm{M}$ & [88] & SS & PCR \\
\hline Arrogante & $\mathrm{SP}$ & Murcia & & $\mathrm{S}$ & $\mathrm{D}$ & [89] & SS & [21] \\
\hline Avikaline & FR & & & $\mathrm{s}$ & M & [15] & SS & WGS \\
\hline Bebecou (Bebeco) & GR & & Unknown [18] & $\mathrm{s}$ & $\mathrm{M} / \mathrm{D}$ & [90] & SS & PCR; $[21,28]$ \\
\hline Bella Di Imola & IT & & Spontaneous seedling [23] & $\mathrm{s}$ & $\mathrm{D}$ & [64] & SS & [28] \\
\hline Bergeron & FR & Saint-Cyr-au-Mont-d'Or, Lyon & Spontaneous seedling [23] & $\mathrm{S}$ & $\mathrm{M}$ & {$[90]$} & SS & PCR; [21] \\
\hline Big Red (EA4006) & FR & Escande EARL, France & & $\mathrm{S}$ & M & [57] & RS & [28] \\
\hline BO04624042 & IT & & Portici × Goldrich [28] & $\mathrm{s}$ & $\mathrm{M}^{*}$ & [28] & SS & [28] \\
\hline BO04624043 & IT & & Portici × Goldrich [28] & $\mathrm{S}$ & $\mathrm{M}^{*}$ & [28] & SS & [28] \\
\hline BO06609003 & IT & & Silvercot $\times$ Bora $[28]$ & $\mathrm{s}$ & $\mathrm{M}^{*}$ & [49] & RS & [49] \\
\hline BO81604311 & IT & & San Castrese $\times$ Reale di Imola [73] & $\mathrm{s}$ & $\mathrm{D}$ & [91] & SS & [24] \\
\hline BO96621021 & IT & & Goldrich $\times$ Lito [28] & $\mathrm{s}$ & $\mathrm{M}^{*}$ & [28] & RS & [28] \\
\hline Boucheran Boutard & FR & & & $\mathrm{s}$ & M & [15] & SS & WGS \\
\hline \multirow{2}{*}{ Búlida } & \multirow{2}{*}{ SP } & \multirow{2}{*}{ Murcia } & \multirow{2}{*}{ Unknown [73] } & \multirow{2}{*}{$\mathrm{S}$} & $\mathrm{D}$ & [92] & \multirow{2}{*}{ SS } & \multirow{2}{*}{ PCR; [21] } \\
\hline & & & & & $\mathrm{M}$ & [93] & & \\
\hline
\end{tabular}


Table 2. Cont

\begin{tabular}{|c|c|c|c|c|c|c|c|c|}
\hline Cultivar & Country $^{a}$ & Origin & Pedigree & $\begin{array}{l}\text { PPV Resistance } \\
\text { Phenotype }^{\mathrm{b}}\end{array}$ & $\begin{array}{l}\text { PPV Strain } \\
\text { Used }\end{array}$ & $\begin{array}{c}\text { First } \\
\text { Phenotype Ref }\end{array}$ & $\begin{array}{c}\text { PMC2 } \\
\text { Genotype }^{c}\end{array}$ & $\begin{array}{c}\text { PMC2 } \\
\text { Genotype Ref }\end{array}$ \\
\hline \multirow{2}{*}{ Cafona } & \multirow{2}{*}{ IT } & \multirow{2}{*}{ Vesuvian area } & & \multirow{2}{*}{$\mathrm{s}$} & $\mathrm{M}$ & [94] & \multirow{2}{*}{ SS } & \multirow{2}{*}{ WGS } \\
\hline & & & & & $\mathrm{D}$ & [64] & & \\
\hline CAID AGDZ n2 & $\mathrm{MO}$ & & & $\mathrm{S}$ & $\mathrm{M}$ & [15] & SS & WGS \\
\hline \multirow{2}{*}{ Canino } & \multirow{2}{*}{ SP } & \multirow{2}{*}{ Valencia } & \multirow{2}{*}{ Unknown [18] } & \multirow{2}{*}{$\mathrm{S}$} & $\mathrm{D}$ & [95] & \multirow{2}{*}{ SS } & \multirow{2}{*}{ PCR; [20,21] } \\
\hline & & & & & $\mathrm{M}$ & [90] & & \\
\hline Castlebrite (=K111-6) & USA & USDA, Fresno, California & $\begin{array}{l}\text { OP seedling of B60-12 }(= \\
\text { Perfection } \times \text { Castleton) [66] }\end{array}$ & $\mathrm{s}$ & $\mathrm{M}$ & {$[45]$} & SS & PCR \\
\hline Ceglédi Bíbor & $\mathrm{HU}$ & Cegléd Horticultural Research Institute & Chance seedling [96] & S & $\mathrm{M}$ & [46] & SS & {$[28]$} \\
\hline \multirow{2}{*}{ Colorado (Colorao 43-15) } & \multirow{2}{*}{ SP } & \multirow{2}{*}{ PSB Producción Vegetal SL } & \multirow{2}{*}{ Unknown } & \multirow{2}{*}{$\mathrm{S}$} & $\mathrm{M}^{*}$ & [49] & \multirow{2}{*}{ SS } & \multirow{2}{*}{ PCR; [28] } \\
\hline & & & & & $\mathrm{D}$ & [89] & & \\
\hline \multirow{2}{*}{ Corbató } & \multirow{2}{*}{ SP } & \multirow{2}{*}{ Valencia } & & \multirow{2}{*}{$\mathrm{S}$} & $\mathrm{D}$ & [95] & \multirow{2}{*}{ SS } & \multirow{2}{*}{ PCR } \\
\hline & & & & & $\mathrm{M}$ & [46] & & \\
\hline \multirow{2}{*}{ Currot } & \multirow{2}{*}{ SP } & \multirow{2}{*}{ Valencia } & \multirow{2}{*}{ Unknown [18] } & & $\mathrm{D}$ & [95] & & \\
\hline & & & & $\mathrm{S}$ & $\mathrm{M}$ & [46] & SS & PCR \\
\hline Estrella & SP & CEBAS-CSIC & $\begin{array}{l}\text { Orange Red } \times \text { Z211-18 }(=\text { Goldrich } \\
\times \text { Pepito del Rubio) }[23]\end{array}$ & $\mathrm{S}$ & $\mathrm{D}$ & [23] & SS & PCR; [49] \\
\hline Faralia & FR & Marie-France BOIS, IPS & & $\mathrm{S}$ & $\mathrm{M}^{*}$ & {$[28]$} & SS & {$[28]$} \\
\hline Farclo & FR & Marie-France BOIS, IPS & & $\mathrm{S}$ & $\mathrm{M}$ & {$[57]$} & SS & {$[28]$} \\
\hline Favorit & RO & & & $\mathrm{S}$ & $\mathrm{M}$ & {$[94,97]$} & SS & [49] \\
\hline Geç Abligoz & TR & & & $\mathrm{S}$ & $\mathrm{T}$ & [61] & SS & [61] \\
\hline & & & & & $\mathrm{D}$ & [95] & & \\
\hline Ginesta & SP & Valencia & Unknown [18] & $\mathrm{S}$ & $\mathrm{M}$ & [46] & SS & PCR \\
\hline Dama Vermella (HG9869) & SP & IVIA & Harcot $\times$ Ginesta [18] & $\mathrm{s}$ & $\mathrm{D}$ & IVIA & SS & PCR; [49] \\
\hline Hacihaliloğlu & TR & & & $\mathrm{S}$ & $\mathrm{T}$ & [61] & SS & [61] \\
\hline Hargrand (= HW410) & C & $\begin{array}{l}\text { Richard EC Layne, Agr. Canada, Res. } \\
\text { Station }\end{array}$ & $\begin{array}{l}\text { V51092 }((\text { Reliable } \times \text { OP }) \times \text { OP }) \times \\
\text { NJA1 }(\text { Phelps } \times \text { Perfection })[66]\end{array}$ & $\mathrm{S}$ & M & [45] & SS & [21] \\
\hline Hasanbey & TR & & & $\mathrm{S}$ & $\mathrm{M}$ & {$[45]^{1}$} & SS & PCR \\
\hline Hungarian Best $=($ Best of & HUI/RO & & & $\mathrm{s}_{\mathrm{s}}$ & $\mathrm{T}$ & [61] & SS & 6611 \\
\hline Hungary?) & HU/RO & & & $\mathrm{s}$ & $\mathrm{M}$ & [94] & SS & {$[61]$} \\
\hline Katy & USA & Zaiger's Genetics ${ }^{4}$ & & $\mathrm{~S}$ & $\mathrm{D}$ & [18] & SS & PCR; [21] \\
\hline Krasnoshchekii & UKR & Advanced/improved cultivar & & $\mathrm{s}$ & $\mathrm{D}$ & [20] & SS & {$[20,21]$} \\
\hline
\end{tabular}


Table 2. Cont

\begin{tabular}{|c|c|c|c|c|c|c|c|c|}
\hline Cultivar & Country $^{a}$ & Origin & Pedigree & $\begin{array}{l}\text { PPV Resistance } \\
\text { Phenotype }^{\text {b }}\end{array}$ & $\begin{array}{l}\text { PPV Strain } \\
\text { Used }\end{array}$ & $\begin{array}{c}\text { First } \\
\text { Phenotype Ref }\end{array}$ & $\begin{array}{c}\text { PMC2 } \\
\text { Genotype }^{c}\end{array}$ & $\begin{array}{c}\text { PMC2 } \\
\text { Genotype Ref }\end{array}$ \\
\hline Kyoto (= Kioto) & FR & Escande & Unknown [73] & $\mathrm{S}$ & $\mathrm{M}^{*}$ & {$[28]$} & SS & {$[28]$} \\
\hline Lambertin-1 & USA & USDA, Fresno, California & $\begin{array}{c}\text { A95-45 × B69-85 (=Perfection } \times \\
\text { Royal) [98] }\end{array}$ & $\mathrm{s}$ & M & [45] & SS & [21] \\
\hline Larclyd (= F168 cv; Jenny Cot) & $\mathrm{NZ}$ & Central Otago & Sundrop $\times$ Moorpark [99] & $\mathrm{S}$ & $\mathrm{M}$ & [15] & SS & WGS \\
\hline Le-3218 & $\mathrm{CR}$ & Faculty of Horticulture in Lednice & Vestar $\times$ SEO [51] & $\mathrm{S}$ & $\mathrm{M}$ & [51] & SS & [24] \\
\hline $\begin{array}{l}\text { Luizet (= Suchet; Hatif du clos; } \\
\text { Abricot du Clos) }\end{array}$ & FR & & Spontaneous seedling [71] & $\mathrm{S}$ & $\mathrm{M}$ & [93] & SS & WGS \\
\hline Luna & IT & & & $\mathrm{s}$ & $\mathrm{M}^{*}$ & {$[28]$} & RS & {$[28]$} \\
\hline Madarska Narijlepsia & SL & & & $\mathrm{S}$ & $\mathrm{M}$ & [15] & SS & WGS \\
\hline Magic cot (= RM 22) & USA & SDR FRUIT LLC - USA & Unknown [23] & $\mathrm{S}$ & $\mathrm{D}$ & [23] & SS & [49] \\
\hline \multirow{2}{*}{ Manicot } & \multirow{2}{*}{ FR } & & & \multirow{2}{*}{$\mathrm{S}$} & $\mathrm{D}$ & {$[97,100]$} & \multirow{2}{*}{ SS } & \multirow{2}{*}{ WGS } \\
\hline & & & & & $\mathrm{M}$ & [15] & & \\
\hline Maravilla & SP & CEBAS-CSIC, Murcia & $\begin{array}{c}\text { Orange Red } \times \text { Z211-18 (= Goldrich } \\
\times \text { Pepito) }[23]\end{array}$ & $\mathrm{s}$ & $\mathrm{D}$ & [23] & SS & PCR; [49] \\
\hline Mari de Cenad & RO & & Unknown & $\mathrm{S}$ & & [86] & RS & PCR \\
\hline Markuleşti & TR & & & $\mathrm{S}$ & $\mathrm{T}$ & [61] & SS & [61] \\
\hline Marlén & $\mathrm{CR}$ & Horticulture Faculty, Lednice & clone of Hungarian Best [59] & $\mathrm{S}$ & $\operatorname{Rec}$ & [14] & SS & PCR; [24] \\
\hline Marouch 14 & $\mathrm{MO}$ & & Local landrace & $\mathrm{s}$ & $\mathrm{M}$ & [15] & SS & WGS \\
\hline Marouch 4 & $\mathrm{MO}$ & & & $\mathrm{s}$ & $\mathrm{M}$ & [15] & SS & WGS \\
\hline Mei Hwang & $\mathrm{CH}$ & & Traditional cultivar/landrace & $\mathrm{s}$ & $\mathrm{M}$ & [15] & SS & WGS \\
\hline Mektep & TR & & & $\mathrm{S}$ & $\mathrm{T}$ & [61] & SS & {$[61]$} \\
\hline Mektep 8 & TR & & & $\mathrm{S}$ & $\mathrm{T}$ & [61] & SS & {$[61]$} \\
\hline \multirow{2}{*}{ Mitger } & \multirow{2}{*}{$\mathrm{SP}$} & \multirow{2}{*}{ Castellón [30] } & \multirow{2}{*}{ Unknown [18] } & \multirow{2}{*}{$S$} & $\mathrm{D}$ & [95] & \multirow{2}{*}{ SS } & \multirow{2}{*}{ PCR } \\
\hline & & & & & $\mathrm{M}$ & [46] & & \\
\hline Monaco Bello & IT & & & $\mathrm{S}$ & $\mathrm{M}$ & [97] & SS & WGS \\
\hline Moniqui & SP & Murcia & Unknown & $\mathrm{S}$ & $\mathrm{M}$ & [90] & SS & PCR; $[21,24]$ \\
\hline Mono & USA & Le Grand, California, by FW Anderson & Perfection OP [66] & $\mathrm{s}$ & $\mathrm{M}$ & [93] & SS & [49] \\
\hline Moongold (= Moongola?) & USA & University of Minessota & & $\mathrm{S}$ & - & [77] & SS & PCR \\
\hline Moorpark (=Moor Park) & USA & & & $\mathrm{s}$ & $\mathrm{M}$ & [46] & SS & WGS \\
\hline Morden 604 & C & $\begin{array}{l}\text { Morden, Manitoba, by Canada Dept. } \\
\text { Agr. Res. Sta. }\end{array}$ & Scout $\times$ McClure [66] & $\mathrm{s}$ & $\mathrm{M}$ & [15] & SS & WGS \\
\hline \multirow{2}{*}{ Ninfa (BO81602075) } & \multirow{2}{*}{ IT } & \multirow{2}{*}{$\begin{array}{c}\text { University of Bologna and Milan, by D. } \\
\text { Bassi }\end{array}$} & \multirow{2}{*}{ Ouardy $\times$ Tyrinthos [55] } & \multirow{2}{*}{$\mathrm{s}$} & $\mathrm{M}^{*}$ & [28] & \multirow{2}{*}{ SS } & \multirow{2}{*}{ PCR; [28,61] } \\
\hline & & & & & $\mathrm{T}$ & [61] & & \\
\hline
\end{tabular}


Table 2. Cont

\begin{tabular}{|c|c|c|c|c|c|c|c|c|}
\hline Cultivar & Country ${ }^{a}$ & Origin & Pedigree & $\begin{array}{l}\text { PPV Resistance } \\
\text { Phenotype }^{\text {b }}\end{array}$ & $\begin{array}{l}\text { PPV Strain } \\
\text { Used }\end{array}$ & $\begin{array}{c}\text { First } \\
\text { Phenotype Ref }\end{array}$ & $\begin{array}{c}\text { PMC2 } \\
\text { Genotype }^{c}\end{array}$ & $\begin{array}{c}\text { PMC2 } \\
\text { Genotype Ref }\end{array}$ \\
\hline Olimp & $\mathrm{RO}$ & & & $\mathrm{S}$ & $\mathrm{M}$ & {$[45]$} & SS & WGS; [49] \\
\hline Orange Rubis (=Couloumine) & FR & Mallard & & $\mathrm{S}$ & $\mathrm{M}$ & [57] & SS & {$[28]$} \\
\hline Ordubat B. & TR & & & $\mathrm{s}$ & $\mathrm{T}$ & {$[61]$} & SS & [61] \\
\hline Ouardi & $\mathrm{TU}$ & INRAT, Ariana & Canino $\times$ Hamidi [101] & $\mathrm{S}$ & $\mathrm{M}$ & [46] & SS & [49] \\
\hline Palsteyn (Palstein) & SA & & Blenhein $\times$ Canino [73] & $\mathrm{S}$ & $\mathrm{M}$ & [102] & SS & WGS \\
\hline \multirow{2}{*}{ Palabras } & \multirow{2}{*}{ SP } & & & \multirow{2}{*}{$\mathrm{s}$} & $\mathrm{D}$ & [95] & \multirow{2}{*}{ SS } & \multirow{2}{*}{ PCR } \\
\hline & & & & & $\mathrm{M}$ & [46] & & \\
\hline Palau & SP & & Unknown [18] & $\mathrm{s}$ & $\mathrm{D}$ & [95] & SS & PCR \\
\hline Paviot & FR & & & $\mathrm{S}$ & $\mathrm{M}$ & [93] & SS & WGS \\
\hline Peche De Nancy & FR & & & $\mathrm{S}$ & $\mathrm{M}$ & [15] & SS & WGS \\
\hline Perfection & USA & Waterville, Washington & Unknown [66] & $\mathrm{S}$ & $\mathrm{M}$ & {$[46]$} & SS & {$[21]$} \\
\hline Piera & & & & $\mathrm{S}$ & $\mathrm{M}$ & {$[65]$} & RS & PCR \\
\hline Poizat & FR & & & $\mathrm{S}$ & $\mathrm{M}$ & [15] & SS & WGS \\
\hline Polonais & FR & & Spontaneous seedling [23] & $\mathrm{s}$ & $\mathrm{M}$ & [93] & SS & [24] \\
\hline Poppy & USA & Zaiger Genetics, Inc., Modesto, CA & 78EB575 × 123GD161 [58] & $\mathrm{s}$ & $\mathrm{D}$ & [23] & SS & [49] \\
\hline \multirow{2}{*}{ Portici (= Pertini) } & \multirow[b]{2}{*}{ IT } & \multirow{2}{*}{ Vesuvian area } & \multirow{2}{*}{ Unknown; Local selection [23] } & \multirow[b]{2}{*}{$\mathrm{s}$} & $\mathrm{M}$ & [46] & \multirow[b]{2}{*}{ SS } & \multirow{2}{*}{ PCR; [28] } \\
\hline & & & & & $\mathrm{D}$ & [64] & & \\
\hline Precoce Ampuis & FR & & & $\mathrm{S}$ & $\mathrm{M}$ & [15] & SS & WGS \\
\hline \multirow{2}{*}{ Reale d'Imola } & \multirow{2}{*}{ IT } & & \multirow{2}{*}{ Luizet OP [23] } & \multirow{2}{*}{$\mathrm{s}$} & $\mathrm{M}$ & [46] & \multirow{2}{*}{ SS } & \multirow{2}{*}[21,24,49]{} \\
\hline & & & & & $\mathrm{D}$ & {$[64]$} & & \\
\hline \multirow{2}{*}{ Rojo de Carlet } & \multirow{2}{*}{ SP } & \multirow{2}{*}{ Valencia } & & \multirow{2}{*}{$\mathrm{S}$} & $\mathrm{D}$ & [95] & \multirow{2}{*}{ SS } & \multirow{2}{*}{ PCR } \\
\hline & & & & & $\mathrm{M}$ & {$[46]$} & & \\
\hline Rouge Du Roussillon & FR & & & $\mathrm{s}$ & $\mathrm{M}$ & [45] & SS & WGS \\
\hline Rouge De Fournes & FR & & & $\mathrm{s}$ & $\mathrm{M}$ & [15] & SS & WGS \\
\hline Saturn & $\mathrm{RO}$ & & & $\mathrm{S}$ & $\mathrm{M}$ & [45] & SS & WGS \\
\hline \multirow{2}{*}{ Screara } & \multirow{2}{*}{ FR } & & & $\mathrm{s}$ & $\mathrm{D}$ & [70] & \multirow{2}{*}{ SS } & \multirow{2}{*}{ WGS } \\
\hline & & & & 3 & $\mathrm{M}$ & [45] & & \\
\hline Şekerpare B. & TR & & & $\mathrm{S}$ & $\mathrm{T}$ & {$[61]$} & SS & {$[61]$} \\
\hline Shalakh (=Yerevani, Erevani) & $\mathrm{AR}$ & & Local selection [23] & $\mathrm{S}$ & $\mathrm{M}$ & {$[93]$} & SS & WGS; [20,21] \\
\hline $\begin{array}{c}\text { Silistra } \times \text { Ananas (Marculesti } \\
43 / 1)\end{array}$ & RO & & & $\mathrm{s}$ & $\mathrm{M}$ & [15] & SS & WGS \\
\hline
\end{tabular}


Table 2. Cont.

\begin{tabular}{|c|c|c|c|c|c|c|c|c|}
\hline Cultivar & Country $^{a}$ & Origin & Pedigree & $\begin{array}{l}\text { PPV Resistance } \\
\text { Phenotype }\end{array}$ & $\begin{array}{l}\text { PPV Strain } \\
\text { Used }\end{array}$ & $\begin{array}{c}\text { First } \\
\text { Phenotype Ref }\end{array}$ & $\begin{array}{c}\text { PMC2 } \\
\text { Genotype }^{c}\end{array}$ & $\begin{array}{c}\text { PMC2 } \\
\text { Genotype Ref }\end{array}$ \\
\hline Sucre De Holub & $\mathrm{HU}$ & Bohême, by M. Holub & & $\mathrm{s}$ & $\mathrm{M}$ & [15] & SS & WGS \\
\hline Sublime & SP & CEBAS-CSIC & $\begin{array}{l}\text { Orange Red } \times \text { Z211-18 (= Goldrich } \\
\times \text { Pepito del Rubio) [103] }\end{array}$ & $\mathrm{s}$ & $\mathrm{D}$ & [103] & SS & PCR; [49] \\
\hline Super Rouge & FR & & & $\mathrm{S}$ & $\mathrm{M}$ & [15] & SS & WGS \\
\hline Sweet Red & FR & & & $\mathrm{S}$ & $\mathrm{M}$ & [57] & SS & [49] \\
\hline $\begin{array}{l}\text { Szegedi mamut (=Szegadti } \\
\text { Mamut?) }\end{array}$ & $\mathrm{HU}$ & Foki István and Kovács Imre & $\begin{array}{l}\text { Hybrid of Cegledi orias, "Giant" } \\
\text { group [96] }\end{array}$ & $\mathrm{s}$ & M & [94] & SS & [49] \\
\hline Tabriz & TR & & & $\mathrm{s}$ & & [86] & SS & PCR \\
\hline \multirow{2}{*}{ Tadeo (= Taddeo) } & \multirow{2}{*}{ SP } & \multirow{2}{*}{ Valencia } & & \multirow{2}{*}{$\mathrm{s}$} & $\mathrm{D}$ & [95] & \multirow{2}{*}{ SS } & \multirow{2}{*}{ PCR } \\
\hline & & & & & M & [45] & & \\
\hline \multirow{2}{*}{ Tardif De Bordaneil } & \multirow{2}{*}{ FR } & & \multirow{2}{*}{ Unknown [23] } & \multirow{2}{*}{$\mathrm{s}$} & $\mathrm{M}$ & [46] & SS & WGS \\
\hline & & & & & $\mathrm{D}$ & [64] & & \\
\hline Tardif De Tain & FR & & & $\mathrm{s}$ & $\mathrm{M}$ & [15] & SS & WGS \\
\hline Tonda di costigliole & IT & Piedmont & & $\mathrm{S}$ & & [104] & SS & [49] \\
\hline Trevatt & $\mathrm{AU}$ & & & $\mathrm{S}$ & $\mathrm{M}$ & {$[45]$} & SS & PCR \\
\hline \multirow{2}{*}{ Tyrinthos } & \multirow{2}{*}{ GR } & & \multirow{2}{*}{ Unknown [18] } & \multirow{2}{*}{$\mathrm{s}$} & $\mathrm{D}$ & [70] & \multirow{2}{*}{ SS } & \multirow{2}{*}{ PCR; WGS; [49] } \\
\hline & & & & & $\mathrm{M}$ & [97] & & \\
\hline Uleanos & SP & Ulea, Murcia & & $\mathrm{S}$ & $\mathrm{D}$ & [89] & SS & [49] \\
\hline Velázquez & SP & Murcia & & $\mathrm{S}$ & $\mathrm{D}$ & [89] & SS & PCR; [21] \\
\hline Venus (= Venus 1414?) & RO & & $\begin{array}{c}(\text { Umberto } \times \text { Ananas }) \times(\text { Luizet } \times \\
\text { Umberto })[96]\end{array}$ & $\mathrm{S}$ & $\mathrm{M}$ & {$[46]$} & SS & [49] \\
\hline Vestar & CR & & $\begin{array}{c}\text { Hungarian Best } \times \text { mixture of } \\
\text { pollen from Chinese cultivars [55] }\end{array}$ & $\mathrm{S}$ & M & [105] & RS & WGS; [24] \\
\hline Vivagold & C & Vineland Station, Ontario & $\begin{array}{c}\text { Veecot } \times \text { V49024 (= Geneva } \times \\
\text { Gibb) [66] }\end{array}$ & $\mathrm{S}$ & $\mathrm{M}$ & [15] & SS & WGS \\
\hline Xirivello (=Chirivello) & $\mathrm{SP}$ & Valencia & Unknown & $\mathrm{s}$ & $\mathrm{M}$ & [46] & SS & PCR \\
\hline Yilbat (=M2243) & TR & & & $\mathrm{s}$ & $\mathrm{T}$ & [61] & RS & [61] \\
\hline
\end{tabular}

$\mathrm{M}^{*}$ : strain likely used for phenotyping by the Phytosanitary Service, Emilia-Romagna (Italy). ${ }^{a}$ Countries: AR: Armenia, AU: Australia, C: Canada, CH: China, CR: Czech Republic, FR: France, GR: Greece, HU: Hungary, IR: Iran, IT: Italy, MO: Morocco, NZ: New Zealand, RO: Romania, SA: South Africa, SL: Slovakia, SP: Spain, TR: Turkey, UKR: Ukraine and US: United States of America; ${ }^{\mathbf{b}}$ Phenotype: R: Resistant, S: Susceptible; ${ }^{\mathbf{c}}$ Genotype: RR: homozygous for PMC2 resistant allele, SS: homozygous for PMC2 susceptible allele and RS: heterozygous. 
Table 3. Apricot accessions with uncertain PPV resistance phenotype genotyped for ParPMC2-del.

\begin{tabular}{|c|c|c|c|c|c|c|c|c|}
\hline Cultivar & Country $^{a}$ & Origin & Pedigree & $\begin{array}{l}\text { PPV Resistance } \\
\text { Phenotype }^{\mathrm{b}}\end{array}$ & $\begin{array}{l}\text { PPV Strain } \\
\text { Used }\end{array}$ & $\begin{array}{l}\text { First Phenotype } \\
\text { Ref }\end{array}$ & $\begin{array}{c}\text { PMC2 } \\
\text { Genotype }^{\mathrm{c}}\end{array}$ & $\begin{array}{c}\text { PMC2 } \\
\text { Genotype Ref }\end{array}$ \\
\hline \multirow[b]{2}{*}{ Badami } & \multirow[b]{2}{*}{ IR } & & & $\mathrm{s}$ & M & \multirow[b]{2}{*}{ [102] } & \multirow{2}{*}{ SS } & \multirow{2}{*}{ WGS } \\
\hline & & & & $\mathrm{T}$ & $\mathrm{D}$ & & & \\
\hline \multirow{2}{*}{ Farbaly } & \multirow{2}{*}{ FR } & \multirow{2}{*}{ Marie-France BOIS, IPS } & & $\mathrm{s}$ & $\mathrm{M}^{*}$ & [28] & \multirow{2}{*}{ RS } & \multirow{2}{*}{ [28] } \\
\hline & & & & $\mathrm{R}$ & M & [56] & & \\
\hline \multirow{5}{*}{ Goldrich } & \multirow{5}{*}{ USA } & \multirow{5}{*}{$\begin{array}{l}\text { USDA and Washington State University, } \\
\text { Prosser, Washington }\end{array}$} & \multirow{5}{*}{ Sun Glo $\times$ Perfection [73] } & \multirow{2}{*}{$\mathrm{R}$} & $\mathrm{D}$ & [68] & \multirow{5}{*}{ RS } & \multirow{5}{*}{$\begin{array}{c}\text { PCR; } \\
{[20,21,24,28]}\end{array}$} \\
\hline & & & & & M & [45] & & \\
\hline & & & & \multirow{2}{*}{ uncertain } & $\mathrm{M}$ & [106] & & \\
\hline & & & & & $\mathrm{D}$ & [68] & & \\
\hline & & & & $\mathrm{s}$ & $\mathrm{D}$ & [64] & & \\
\hline \multirow{4}{*}{ Harcot } & \multirow{4}{*}{ C } & \multirow{4}{*}{$\begin{array}{l}\text { Agr. Canada, Res. Station, Harrow, Ontario, } \\
\text { by REC Layne }\end{array}$} & \multirow{4}{*}{$\begin{array}{l}(\text { T2 }(\text { Geneva } \times \text { Naramata) } \times \text { Morden } 604(\text { Scout } \times \\
\text { McClure) }) \times \text { NJA1 (Phelps } \times \text { Perfection) [66] }\end{array}$} & $\mathrm{T} ?$ & - & [28] & \multirow{3}{*}{ RS } & \multirow{3}{*}{ PCR; $[21,24,28]$} \\
\hline & & & & & $\mathrm{M}$ & [90] & & \\
\hline & & & & R & $\mathrm{D}$ & [70] & & \\
\hline & & & & $\mathrm{s}$ & $\mathrm{T}$ & [61] & SS & [61] \\
\hline \multirow{2}{*}{$\begin{array}{c}\text { Incomparable de Malissard } \\
\text { (= Valssard) }\end{array}$} & \multirow{2}{*}{ FR } & \multirow{2}{*}{ Malissard, Valence } & & $\mathrm{R}$ & \multirow{2}{*}{ M } & [15] & \multirow{2}{*}{ RS } & WCS \\
\hline & & & & $\mathrm{S}$ & & [57] & & WGS \\
\hline & & & & $\mathrm{s}$ & $\mathrm{M}^{*}$ & [28] & & \\
\hline Piom & IT & & JCAPI 26/5OP [55] & $\mathrm{R}$ & $\mathrm{M}$ & [65] & $s c$ & PCP. [28] \\
\hline (1) & 11 & & 的 & $\mathrm{R}$ & $\mathrm{D}$ & [64] & 30 & $1 \in(x,[<0]$ \\
\hline & & & & $\mathrm{S}$ & $\mathrm{D}$ & [28] & & \\
\hline Pieve (BO89608015) & IT & University of Bologn and Milan be $\mathrm{D}$ Bassi & Harcot $\times$ Reale di Jmola [73] & $\mathrm{S}$ & $\mathrm{M}^{*}$ & [28] & & [28] \\
\hline Pieve (BO89008015) & 11 & Unversity or boiogna and inilan, by D. Dassi & Harcot $X$ Keale al imola $[/ 3]$ & $\mathrm{R}$ & $\mathrm{M}$ & [65] & SS & {$[28]$} \\
\hline & & Naples & & $\mathrm{T}$ & $\mathrm{D}$ & [64] & & \\
\hline San Castrese & IT & Naples & Unknown [73] & $\mathrm{S}$ & $\mathrm{M}$ & [46] & SS & WGS; [49] \\
\hline & & & & $\mathrm{S}$ & $\mathrm{M}$ & [45] & & [49] \\
\hline Sulmona & RO & & (Luizet $\times$ Re Umberto $) \times($ Ananas $\times$ Ananas) $[7 /]$ & $\mathrm{R}$ & - & [77] & SS & [49] \\
\hline & & & & $\mathrm{R}$ & & [45] & & \\
\hline Veecot & C & $\begin{array}{c}\text { Ontario Dept Agr Res Inst, Vineland Station, } \\
\text { Ontario, by OA Bradt }\end{array}$ & Reliable OP [18] & $\mathrm{S}$ & M & [105] & RS & PCR; [21] \\
\hline & & & & $\mathrm{T}$ & $\mathrm{D}$ & [47] & & \\
\hline 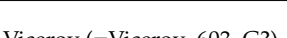 & & & & $\mathrm{R}$ & - & [77] & & \\
\hline Viceroy (=Viceroy_603_G? & RO & & & $\mathrm{s}$ & - & [86] & SS & PCR \\
\hline
\end{tabular}

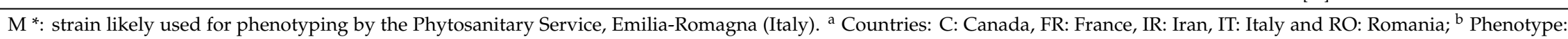

R: Resistant and S: Susceptible; and ${ }^{\mathrm{C}}$ Genotype: RR: homozygous for PMC2 resistant allele, SS: homozygous for PMC2 susceptible allele and RS: heterozygous. 
Accurate evaluation of PPV resistance is a complex process, and results obtained by different researchers sometimes are contradictory, as exemplified by Farbaly and Pieve (Table 3), which may lead to GPIs. This problem is also observed in well-known accessions. For instance, Goldrich, usually classified as resistant against both PPV-D and M strains, has also been classified as uncertain or even as susceptible at least once (Table 3). Moreover, the effect of the PPV strain used [9,24] has also been observed, as at least 5 accessions showed different behaviour against PPV-M, D or T infection (Table 3). In addition, the environmental effect on symptoms and the different PPV detection techniques employed could also been involved in GPIs [9].

On the other hand, PPV resistance has been related with the downregulation of both ParPMC2 and, especially, ParPMC1, putatively due to an RNA silencing mechanism triggered by the pseudogenization of ParPMC2res [21]. Notwithstanding, the presence of epigenetic changes has also been suggested as a possible cause [22]. In any case, resistant cultivars show residual expression levels that could somehow be influenced by environmental conditions. This might explain sporadic symptoms that eventually lead to GPI classification. Moreover, the role of additional PPV resistance loci or genes may also contribute to GPIs. In this sense, Gallois et al. [105] pointed out that a large part of a resistant phenotype conferred by a given QTL depends on the genetic background due to frequent epistatic effects between resistance genes. In fact, other minor loci, linked or not to PPVres, have been suggested to underlie PPV resistance in apricot [13-16]. Altogether, the identification and/or confirmation of GPIs in this work pave the way for future studies to unravel the PPV resistance mechanism.

The handful of North American cultivars originally described as PPV resistant [9] have been extensively used as donors in all breeding programs currently in progress. As a result, the PPVres locus has been introduced in different genetic backgrounds. In order to complete our survey, genotypic information was compiled from other 96 accessions without available PPV phenotype data (Table S1, [107-113]). In summary, 152 accessions (46.8\%) have at least one copy of the ParPMC2-del (Figure 3) and 15 out of them are homozygous for ParPMC2-del, including the North American PPV-resistant cultivar Stella [114]. Those materials derived from crosses with North American PPV-resistant cultivars represent an opportunity to accelerate the development of new varieties better adapted to the Mediterranean basin conditions [9]. In this context, it should be highlighted that MAS allows to improve cost efficiency and/or genetic gain in apricot breeding programs aimed to select PPV-resistant seedlings. This improvement is highly significant even if some PPV susceptible individuals among those with ParPMC2-del are dragged, since they will be later identified by PPV phenotyping. Similarly, Tartarini et al. [115] underlined the advantage of the identification of homozygous Rvi6 scab-resistant plants using MAS, despite segregating progenies showing at least $5 \%$ of GPIs.

\section{Conclusions}

Here, we present a high-throughput method to quickly perform DNA testing for PPV resistance that may greatly improve the efficiency of apricot breeding programs. The long-lasting PPV phenotyping process will only be performed with those advanced selections showing promising agronomic behaviour in advanced stages to guarantee the selection of PPV-resistant individuals. Additionally, a wide survey over 300 accessions has been made to identify PPV-resistant sources that could also be useful in apricot breeding programs.

Supplementary Materials: The following are available online at http://www.mdpi.com/2073-4395/10/9/1292/s1, Table S1. PMC2 genotyped apricot accessions without phenotypic data against PPV infection; Table S2. Estimation cost of DNA extraction and PMC genotyping for PPV MAS in apricot.

Author Contributions: Conceptualization: C.R., M.L.B. and E.Z.; experimental procedures: Á.P.-O., I.L. and E.Z.; bioinformatics: E.Z.; funding acquisition: M.L.B.; writing—original draft, E.Z.; writing—review and editing, Á.P.-O., C.R., I.L., M.L.B. and E.Z. All authors have read and agreed to the published version of the manuscript. 
Funding: This research was funded by the Instituto Nacional de Investigación y Tecnología Agraria y Alimentaria (INIA)-FEDER (RTA2017-00011-C03-01). Á.P.O. was funded by a fellowship cofinanced by the Generalitat Valenciana and European Social Fund (2014-2020) (DOCV 8426/19.11.2018).

Acknowledgments: The authors would like to express their gratitude to Bassi (University of Milan, Italy) for providing pedigree information from their apricot breeding program.

Conflicts of Interest: The authors declare no conflict of interest. The funders had no role in the design of the study; in the collection, analyses or interpretation of data; in the writing of the manuscript; or in the decision to publish the results.

\section{References}

1. Rehder, A. Manual of Cultivated Trees and Shrubs Hardy in North America, 2nd ed.; The Macmillan Company: New York, NY, USA, 1940.

2. Zhebentyayeva, T.N.; Ledbetter, C.; Burgos, L.; Llácer, G. Apricots. In Fruit Breeding, 1st ed.; Badenes, M.L., Byrne, D.H., Eds.; Springer: New York, NY, USA, 2012; Volume 3, pp. 415-458. [CrossRef]

3. Moreno, M.A. Breeding and selection of Prunus rootstocks at the Aula Dei experimental station, Zaragoza, Spain. Acta Hortic. 2004, 658, 519-528. [CrossRef]

4. García, J.A.; Cambra, M. Plum pox virus and sharka disease. Plant. Viruses 2007, 1, 69-79.

5. García, J.A.; Glasa, M.; Cambra, M.; Candresse, T. Plum pox virus and sharka: A model potyvirus and a major disease. Mol. Plant. Pathol. 2014, 15, 226-241. [CrossRef]

6. Chirkov, S.; Ivanov, P.; Sheveleva, A.; Zakubanskiy, A.; Osipov, G. New highly divergent Plum pox virus isolates infecting sour cherry in Russia. Virology 2017, 502, 56-62. [CrossRef]

7. James, D.; Varga, A.; Sanderson, D. Genetic diversity of Plum pox virus: Strains, disease and related challenges for control. Can. J. Plant. Pathol. 2013, 35, 431-441. [CrossRef]

8. Sihelská, N.; Glasa, M.; Šubr, Z.W. Host preference of the major strains of Plum pox virus-Opinions based on regional and world-wide sequence data. J. Integr. Agric. 2017, 16, 510-515. [CrossRef]

9. Martínez-Gómez, P.; Dicenta, F.; Audergon, J.M. Behaviour of apricot (Prunus armeniaca L.) cultivars in the presence of Sharka (Plum pox potyvirus): A review. Agronomie 2000, 20, 407-422. [CrossRef]

10. Dondini, L.; Lain, O.; Vendramin, V.; Rizzo, M.; Vivoli, D.; Adami, M.; Guidarelli, M.; Gaiotti, F.; Palmisano, F.; Bazzoni, A.; et al. Identification of QTL for resistance to Plum pox virus strains M and D in Lito and Harcot apricot cultivars. Mol. Breed. 2011, 27, 289-299. [CrossRef]

11. Hurtado, M.A.; Romero, C.; Vilanova, S.; Abbott, A.G.; Llácer, G.; Badenes, M.L. Genetic linkage maps of two apricot cultivars (Prunus armeniaca L.) and mapping of PPV (sharka) resistance. Theor. Appl. Genet. 2002, 105, 182-191. [CrossRef]

12. Lalli, D.A.; Abbott, A.G.; Zhebentyayeva, T.N.; Badenes, M.L.; Damsteegt, V.; Polák, J.; Krška, B.; Salava, J. A genetic linkage map for an apricot (Prunus armeniaca L.) BC1 population mapping Plum pox virus resistance. Tree Genet. Genomes 2008, 4, 481-493. [CrossRef]

13. Lambert, P.; Dicenta, F.; Rubio, M.; Audergon, J.M. QTL analysis of resistance to sharka disease in the apricot (Prunus armeniaca L.) 'Polonais' x 'Stark Early Orange' F1 progeny. Tree Genet. Genomes 2007, 3, $299-309$. [CrossRef]

14. Marandel, G.; Pascal, T.; Candresse, T.; Decroocq, V. Quantitative resistance to Plum pox virus in Prunus davidiana P1908 linked to components of the eukaryotic translation initiation complex. Plant. Pathol. 2009, 58, 425-435. [CrossRef]

15. Mariette, S.; Wong Jun Tai, F.; Roch, G.; Barre, A.; Chague, A.; Decroocq, S.; Groppi, A.; Laizet, Y.; Lambert, P.; Tricon, D.; et al. Genome-wide association links candidate genes to resistance to Plum pox virus in apricot (Prunus armeniaca). New Phytol. 2016, 209, 773-784. [CrossRef]

16. Pilarova, P.; Marandel, G.; Decroocq, V.; Salava, J.; Krška, B.; Abbott, A.G. Quantitative trait analysis of resistance to Plum pox virus in the apricot F1 progeny 'Harlayne' x 'Vestar'. Tree Genet. Genomes 2010, 6, 467-475. [CrossRef]

17. Soriano, J.M.; Vera-Ruiz, E.; Vilanova, S.; Martínez-Calvo, J.; Llácer, G.; Badenes, M.L.; Romero, C. Identification and mapping of a locus conferring Plum pox virus resistance in two apricot-improved linkage maps. Tree Genet. Genomes 2008, 4, 391-402. [CrossRef] 
18. Soriano, J.M.; Domingo, M.L.; Zuriaga, E.; Romero, C.; Zhebentyayeva, T.; Abbott, A.G.; Badenes, M.L. Identification of simple sequence repeat markers tightly linked to Plum pox virus resistance in apricot. Mol. Breed. 2012, 30, 1017-1026. [CrossRef]

19. Zhebentyayeva, T.N.; Reighard, G.L.; Lalli, D.; Gorina, V.M.; Krška, B.; Abbott, A.G. Origin of resistance to Plum pox virus in apricot: What new AFLP and targeted SSR data analyses tell. Tree Genet. Genomes 2008, 4, 403-417. [CrossRef]

20. Zuriaga, E.; Soriano, J.M.; Zhebentyayeva, T.; Romero, C.; Dardick, C.; Cañizares, J.; Badenes, M.L. Genomic analysis reveals MATH gene(s) as candidate(s) for Plum pox virus (PPV) resistance in apricot (Prunus armeniaca L.). Mol. Plant Pathol. 2013, 14, 663-677. [CrossRef]

21. Zuriaga, E.; Romero, C.; Blanca, J.M.; Badenes, M.L. Resistance to Plum pox virus (PPV) in apricot (Prunus armeniaca L.) is associated with down-regulation of two MATHd genes. BMC Plant Biol. 2018, 18, 25. [CrossRef]

22. Rodamilans, B.; Valli, A.; García, J.A. Molecular plant-Plum pox virus interactions. Mol. Plant. Microbe Interact. 2020, 33, 6-17. [CrossRef]

23. Rubio, M.; Ruiz, D.; Egea, J.; Martínez-Gómez, P.; Dicenta, F. Opportunities of marker assisted selection for Plum pox virus resistance in apricot breeding programs. Tree Genet. Genomes 2014, 10, 513-525. [CrossRef]

24. Decroocq, S.; Chague, A.; Lambert, P.; Roch, G.; Audergon, J.M.; Geuna, F.; Chiozzotto, R.; Bassi, D.; Dondini, L.; Tartarini, S.; et al. Selecting with markers linked to the PPVres major QTL is not sufficient to predict resistance to Plum pox virus (PPV) in apricot. Tree Genet. Genomes 2014, 10, 1161-1170. [CrossRef]

25. Moustafa, T.A.; Badenes, M.L.; Martínez-Calvo, J.; Llácer, G. Determination of resistance to sharka (plum pox) virus in apricot. Sci. Hort. 2001, 91, 59-70. [CrossRef]

26. Lommel, S.A.; McCain, A.H.; Morris, T.J. Evaluation of indirect-linked immunosorbent assay for the detection of plant viruses. Phytopathology 1982, 72, 1018-1022. [CrossRef]

27. Wetzel, T.; Candresse, T.; Ravelonandro, M.; Dunez, J. A polymerase chain reaction assay adapted to plum pox potyvirus detection. J. Virol. Methods 1991, 33, 355-365. [CrossRef]

28. Passaro, M.; Geuna, F.; Bassi, D.; Cirilli, M. Development of a high-resolution melting approach for reliable and cost-effective genotyping of PPVres locus in apricot (P. armeniaca). Mol. Breed. 2017, 37, 74. [CrossRef]

29. Ru, S.; Main, D.; Evans, K.; Peace, C. Current applications, challenges, and perspectives of marker-assisted seedling selection in Rosaceae tree fruit breeding. Tree Genet. Genomes 2015, 11, 8. [CrossRef]

30. Doyle, J.J.; Doyle, J.L. A rapid isolation procedure for small quantities of fresh leaf tissue. Phytochem. Bull. 1987, 19, 11-15.

31. Muñoz-Sanz, J.V.; Zuriaga, E.; Badenes, M.L.; Romero, C. A disulfide bond A-like oxidoreductase is a strong candidate gene for self-incompatibility in apricot (Prunus armeniaca) pollen. J. Exp. Bot. 2017, 68, 5069-5078. [CrossRef]

32. Haas, B.J.; Papanicolaou, A.; Yassour, M.; Grabherr, M.; Blood, P.D.; Bowden, J.; Couger, M.B.; Eccles, D.; Li, B.; Lieber, M.; et al. De novo transcript sequence reconstruction from RNA-seq using the trinity platform for reference generation and analysis. Nat. Protoc. 2013, 8, 1494-1512. [CrossRef]

33. Verde, I.; Jenkins, J.; Dondini, L.; Micali, S.; Pagliarani, G.; Vendramin, E.; Paris, R.; Aramini, V.; Gazza, L.; Rossini, L.; et al. The Peach v2.0 release: High-resolution linkage mapping and deep resequencing improve chromosome-scale assembly and contiguity. BMC Genom. 2017, 18, 225. [CrossRef] [PubMed]

34. Langmead, B.; Salzberg, S.L. Fast gapped-read alignment with bowtie 2. Nat. Meth. 2012, 9, 357-359. [CrossRef] [PubMed]

35. Thorvaldsdóttir, H.; Robinson, J.T.; Mesirov, J.P. Integrative Genomics Viewer (IGV): High-performance genomics data visualization and exploration. Brief. Bioinform. 2013, 14, 178-192. [CrossRef] [PubMed]

36. Peace, C. DNA-informed breeding of rosaceous crops: Promises, progress and prospects. Hortic. Res. 2017, 4, 17006. [CrossRef]

37. Edge-Garza, D.A.; Luby, J.J.; Peace, C. Decision support for cost-efficient and logistically feasible marker-assisted seedling selection in fruit breeding. Mol. Breed. 2015, 35, 223. [CrossRef]

38. Audergon, J.M.; Blanc, A.; Gilles, F.; Broquaire, J.M.; Clauzel, G.; Gouble, B.; Grotte, M.; Reich, M.; Bureau, S.; Pitiot, C. New recent selections issued from INRA's apricot breeding programme. Acta Hortic. 2010, 862, 179-182. [CrossRef] 
39. Bassi, D.; Audergon, J.M. Apricot breeding: Update and perspectives. Acta Hortic. 2006, 701, 279-294. [CrossRef]

40. Bassi, D.; Bellini, E.; Guerriero, R.; Monastra, F.; Pennone, F. Apricot breeding in Italy. Acta Hortic. 1995, 384, 47-54. [CrossRef]

41. Egea, J.; Dicenta, F.; Burgos, L.; Martínez-Gómez, P.; Rubio, M.; Campoy, J.A.; Ortega, E.; Patiño, J.L.; Nortes, L.; Molina, A.; et al. New apricot cultivars from CEBAS-CSIC (Murcia, Spain) breeding programme. Acta Hortic. 2010, 862, 113-118. [CrossRef]

42. Martínez-Calvo, J.; Font, A.; Llácer, G.; Badenes, M.L. Apricot and Peach breeding programs from the IVIA. Acta Hortic. 2009, 814, 185-188. [CrossRef]

43. Gürcan, K.; Ceylan, A. Strain identification and sequence variability of Plum pox virus in Turkey. Turkish J. Agric. 2016, 40, 746-760. [CrossRef]

44. Decroocq, S.; Cornille, A.; Tricon, D.; Babayeva, S.; Chague, A.; Eyquard, J.P.; Karychev, R.; Dolgikh, S.; Kostritsyna, T.; Li, S.; et al. New insights into the history of domesticated and wild apricots and its contribution to Plum pox virus resistance. Mol. Ecol. 2016, 25, 4712-4729. [CrossRef] [PubMed]

45. Dosba, F.; Orliac, S.; Dutranoy, F.; Maison, P.; Massonie, G.; Audergon, J.M. Evaluation of resistance to Plum pox virus in apricot trees. Acta Hortic. 1992, 309, 211-219. [CrossRef]

46. Karayiannis, I.; Mainou, A. Resistance to Plum pox virus in apricots. EPPO Bull. 1994, 24, 761-766. [CrossRef]

47. Martínez-Gómez, P.; Rubio, M.; Dicenta, F. Evaluation of resistance to Plum pox virus of North American and European apricot cultivars. HortScience 2003, 38, 568-569. [CrossRef]

48. Egea, J.; Rubio, M.; Campoy, J.A.; Dicenta, F.; Ortega, E.; Nortes, M.D.; Martínez-Gómez, P.; Molina, A.; Molina, A., Jr.; Ruiz, D. 'Mirlo Blanco', 'Mirlo Anaranjado', and 'Mirlo Rojo': Three new very early-season apricots for the fresh market. HortScience 2010, 45, 1893-1894. [CrossRef]

49. Passaro, M. Cost-Effective Use of Molecular Markers in the Practical Resolution of Common Horticultural Challenges. Ph.D. Thesis, Agriculture, Environment and Bioenergy in Universitá Degli Studi Di Milano, Milan, Italy, 2016.

50. Krška, B.; Salava, J.; Polák, J. Breeding for resistance: Breeding for Plum pox virus resistant apricots (Prunus armeniaca L.) in the Czech Republic. EPPO Bull. 2006, 36, 330-331. [CrossRef]

51. Krška, B.; Salava, J.; Polák, J.; Komínek, P. Genetics of resistance to Plum pox virus in apricot. Plant Protect. Sci. 2002, 38, 180-182. [CrossRef]

52. Krška, B.; Vachun, Z.; Nečas, T.; Ondrásek, I. New Sharka resistant apricots at the Horticultural Faculty in Lednice. Acta Hortic. 2015, 1063, 105-110. [CrossRef]

53. Rankovic, M.; Duli-Markovic, I.; Paunovic, S. Sharka virus in apricot and its diagnosis. Acta Hortic. 1999, 488, 783-786. [CrossRef]

54. CEP INNOVATION Website. Available online: https://cepinnovation-novadi.com/variete/anegat/ (accessed on 29 July 2020).

55. Milatović, D.; Nikolić, D.; Krška, B. Testing of self-(in)compatibility in apricot cultivars from European breeding programmes. HortScience 2013, 40, 65-71. [CrossRef]

56. Brans, Y. Evaluation de la sensibilité de cultivars d'abricotier à la Sharka en zone confinée. Présentation de l'essai Ctifl 2012-2015. In Proceedings of the Rencontres Phytosanitaires Ctifl/DGAL—SDQPV Fruits à Noyau Ctifl Balandran, Bellegarde, France, 16 October 2016.

57. Babini, A.R.; Vicchi, V.; Missere, D. L'esame delle cultivar tolleranti alla sharka. Ermes Agricoltura 2010. Available online: http://www.crpv.it/doc/549738/DLFE-9612.pdf (accessed on 29 August 2020).

58. Finn, C.E.; Clark, J.R. Register of New Fruit and Nut Cultivars List 44. HortScience 2008, 43, $1321-1343$. [CrossRef]

59. Krška, B.; Vachůn, Z. Apricot Breeding at the Faculty of Horticulture in Lednice. Agronomy 2016, 6, 27. [CrossRef]

60. Krška, B. Genetic resources of apricot for adaptability improvement and breeding. Acta Hortic. 2010, 862, 203-208. [CrossRef]

61. Gürcan, K.; Çetinsağ, N.; Pınar, H.; Macit, T. Molecular and biological assessment reveals sources of resistance to Plum pox virus-Turkey strain in Turkish apricot (Prunus armeniaca) germplasm. Sci. Hortic. 2019, 252, 348-353. [CrossRef] 


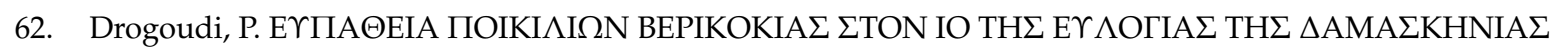

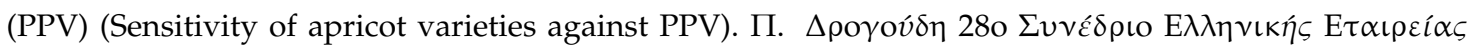

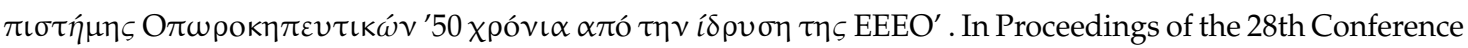
of the Hellenic Fruit and Vegetable Credit Society '50 Years Since the Founding of EEEO', Thessaloniki, Greece, 16-20 October 2017.

63. Goffreda, J.C.; Voordeckers, A.; Butenis-Vorsa, L.; Cowgill, W.P., Jr.; Maletta, M.H.; Frecon, J.L. NJA53 apricot. HortScience 1995, 30, 389-390. [CrossRef]

64. Faggioli, F.; Barba, M. Screening of stone fruit germplasm for resistance to Plum Pox Potyvirus. Adv. Hortic. Sci. 1996, 10, 91-94.

65. Poggi Pollini, C.; Bianchi, L.; Babini, A.; Vicchi, V.; Liverani, A.; Brandi, F.; Giunchedi, L.; Autonell, C.; Ratti, C. Evaluation of Plum pox virus infection on different stone fruit tree varieties. J. Plant. Pathol. 2008, 90, S27-S31.

66. Brooks, R.M.; Olmo, H.P. The Brooks and Olmo Register of Fruit and Nut Varieties, 3rd ed.; ASHS Press: Alexandria, VA, USA, 1997.

67. Leccese, A.; Bartolini, S.; Viti, R. Genotype harvest season, and cold storage influence on fruit quality and antioxidant properties of apricot. Int. J. Food Prop. 2012, 15, 864-879. [CrossRef]

68. Fuchs, E.; Grünzig, M.; Kegler, H. Investigation on the Plum pox virus resistance in different apricot genotypes. Acta Virol. 1998, 42, 222-225.

69. Polák, J.; Oukropec, I.; Krška, B.; Pívalová, J.; Miller, W. Difference in reactions of apricot and peach cultivars to Plum pox virus: Serological and symptomatological evaluation. HortScience 2003, 30, 129-134. [CrossRef]

70. Audergon, J.M.; Dosba, F.; Karayiannis, I.; Dicenta, F. Amélioration de l'abricotier pour la résistance à la sharka. EPPO Bull. 1994, 24, 741-748. [CrossRef]

71. Mesarović, J.; Trifković, J.; Tosti, T.; Akšić, M.F.; Milatović, D.; Ličina, V.; Milojković-Opsenica, D. Relationship between ripening time and sugar content of apricot (Prunus armeniaca L.) kernels. Acta Physiol. Plant. 2018, 40, 157. [CrossRef]

72. Krška, B.; Oukropec, I.; Polak, J.; Kominek, P. The evaluation of apricot (Prunus armeniaca L.) cultivars and hybrids resistant to Sharka. Acta Hortic. 2000, 538, 143-146. [CrossRef]

73. Salazar, J.A.; Rubio, M.; Ruiz, D.; Tartarini, S.; Martínez-Gómez, P.; Dondini, L. SNP development for genetic diversity analysis in apricot. Tree Genet. Genomes 2015, 11, 15. [CrossRef]

74. Syrgiannidis, G.; Mainou, A. Two new apricot varieties resistant to Sharka (Plum pox virus) disease created by crossing. In Agriculure, Proceedings of the Programme de recherche Agrimed. Deuxiemes Rencontres sur L'abricotier, Avignon, France, 27-31 May 1991; CEC Commission of the European Communities: Luxembourg, 1993.

75. Egea, J.; Ruiz, D.; Dicenta, F.; Burgos, L. Murciana apricot. HortScience 2005, 40, 254-255. [CrossRef]

76. Ledbetter, C.A.; Peterson, S.J. 'Apache' and 'Kettleman': Two early season apricots for the fresh market. HortScience 2005, 40, 2202-2203. [CrossRef]

77. Trandafirescu, M.; Dumitru, L.M.; Trandafirescu, I. Evaluating the Resistance to the Plum pox virus of Some Apricot Tree Cultivars and Hybrids in South-Eastern Romania. Proc. Latvian Acad. Sci. 2013, 67, $203-206$. [CrossRef]

78. Egea, J.; Ruiz, D.; Martínez-Gómez, P. Influence of rootstock on the productive behaviour of 'Orange Red' apricot under Mediterranean conditions. Fruits 2004, 59, 367-373. [CrossRef]

79. Karayannis, I.; Di Terlizzi, B.; Audergon, J.M. Susceptibility of apricot cultivars to Plum pox virus. Acta Hortic. 1999, 488, 753-760. [CrossRef]

80. Halász, J. Molecular Background of the S-locus Controlled Self-Incompatibility in Apricot. Ph.D. Thesis, Department of Genetics and Plant Breeding, Corvinus University, Budapest, Hungary, 2007.

81. Ledbetter, C.A.; Ramming, D.W. Apricot cv. Robada. United. States Patent USPP9890P, 13 May 1997.

82. Karayiannis, I.; Ledbetter, C.A. Susceptibility of certain apricot and plumcot cultivars to Plum pox virus infection. Acta Hortic. 2009, 825, 153-156. [CrossRef]

83. Egea, J.; Dicenta, F.; Burgos, L. 'Rojo Pasión' Apricot. HortScience 2004, 39, 1490-1491. [CrossRef]

84. Egea, J.; Dicenta, F.; Martínez-Gómez, P.; Burgos, L. Selene apricot. HortScience 2004, 39, 192-1493. [CrossRef]

85. Syrgiannidis, G. Selection of two apricot varieties resistant to Sharka virus. Acta Phytopathol. Acad. Sci. Hung. 1980, 15, 85-87. [CrossRef]

86. Adascalului, M.; Hoza, D.; Ion, L. Behaviour study for pollination a Romanian apricot varieties using different source of resistance to Sharka. J. Hortic. For. Biotechnol. 2014, 18, 13-17. 
87. Ion, L.; Asănică, A.; Moale, C. Studies of resistance to Sharka in several Romanian apricot progenies. In Proceedings of the International Conference on Chemical, Agricultural and Biological Sciences (CABS-2015), Istanbul, Turkey, 4-5 September 2015.

88. Elibüyük, S.; Erdiller, G. The susceptibility of some apricot and plum varieties to Plum pox (sharka) virus. Acta Hortic. 1995, 384, 549-552. [CrossRef]

89. Rodríguez, J.; Andrés, V.; Gil, L.; Martínez, J.; Hita, I. Sensibilidad a Sharka en Variedades de Albaricoquero de Murcia; Frutales Hueso Fund. La Caixa: Barcelona, Spain, 1995; pp. 56-64.

90. Dosba, F.; Lansac, M.; Maison, P.; Massonie, G.; Audergon, J.M. Tolerance to Plum pox virus in apricot. Acta Hort. 1988, 235, 275-281. [CrossRef]

91. Dondini, L.; Lain, O.; Geuna, F.; Banfi, R.; Gaiotti, F.; Tartarini, S.; Bassi, D.; Testolin, R. Development of a new SSR-based linkage map in apricot and analysis of synteny with existing Prunus maps. Tree Genet. Genomes 2007, 3, 239-249. [CrossRef]

92. Martínez-Gómez, P.; Dicenta, F. Evaluation of resistance of apricot cultivars to a Spanish isolate of plum pox potyvirus (PPV). Plant. Breed. 2000, 119, 179-181. [CrossRef]

93. Karayiannis, I. Susceptibility of apricots cultivars to Plum pox virus in Greece. Acta Hortic. 1989, 235, $271-274$. [CrossRef]

94. Balan, V.; Stoian, E. Susceptibility of certain apricot-tree to the Plum pox virus pathogenic action. Acta Hortic. 1995, 384, 565-569. [CrossRef]

95. Avinent, L.; Hermoso de Mendoza, A.; Llácer, G.; García, S. Transmisión del virus de la sharka y sensibilidad varietal en albaricoquero. In Proceedings of the II Congreso Ibérico Ciencias Hortícolas, Zaragoza, Spain, 27-30 April 1993.

96. Maghuly, F.; Borroto-Fernandez, E.; Ruthner, S.; Pedryc, A.; Laimer, M. Microsatellite variability in apricots (Prunus armeniaca L.) reflects their geographic origin and breeding history. Tree Genet. Genomes 2005, 1, 151-165. [CrossRef]

97. Audergon, J.M.; Morvan, G.; Dicenta, F.; Chastelliere, G.; Karayiannis, I. A method to determine the susceptibility of apricot to Plum pox virus. Acta Hortic. 1995, 384, 575-579. [CrossRef]

98. Egea, J.; Burgos, L. Detecting cross-incompatibility of three North American apricot cultivars and establishing the first incompatibility group in apricot. J. Am. Soc. Hort. Sci. 1996, 121, 1002-1005. [CrossRef]

99. McLaren, J. Apricot tree, 'F168 cv'. United. States Patent USPP16071P2, 25 October 2005.

100. Dicenta, F.; Audergon, J.M. Localization of Plum pox virus (PPV) in tissues of susceptible and resistant apricot cultivars. Phytopathol. Med. 1995, 34, 83-87.

101. Lachkar, A.; Mlika, M. New apricot varieties selected from the Tunisian breeding programme. Acta Hort. 2006, 717, 189-192. [CrossRef]

102. Dosba, F.; Denise, F.; Audergon, J.M.; Maison, P.; Massonie, G. Plum pox virus resistance of apricot. Acta Hortic. 1991, 293, 569-580. [CrossRef]

103. Egea, J.; Campoy, J.A.; Dicenta, F.; Burgos, L.; Patiño, J.L.; Ruiz, D. ‘Estrella' and 'Sublime' apricot cultivars. HortScience 2009, 44, 469-470. [CrossRef]

104. Eynard, A.; Roggero, P.; Lenzi, R.; Conti, M.; Milne, R.G. Test for pollen and seed transmission on Plum pox virus (Sharka) in two apricot cultivars. Adv. Hortic. Sci. 1991, 5, 104-106.

105. Gallois, J.L.; Moury, B.; German-Retana, S. Role of the Genetic Background in Resistance to Plant Viruses. Int. J. Mol. Sci. 2018, 19, 2856. [CrossRef]

106. Polák, J.; Kominek, P.; Jokes, M.; Oukropec, I.; Krška, B. The evaluation of resistance of apricots to Plum pox virus by ELISA and ISEM. Acta Hortic. 1995, 386, 285-289. [CrossRef]

107. Layne, R.E.C.; Hunter, D.M. 'AC Harostar' apricot. HortScience 2003, 38, 140-141. [CrossRef]

108. Hegedûs, A.; Lénárt, J.; Halász, J. Sexual incompatibility in Rosaceae fruit tree species: Molecular interactions and evolutionary dynamics. Biol. Plant 2012, 56, 201-209. [CrossRef]

109. Austin, P.T. Pollination of Sundrop Apricot. Ph.D. Thesis, Massey University, Auckland, New Zealand, 1995.

110. Egea, J.; Ruiz, D.; Burgos, L. “Dorada” apricot. HortScience 2005, 40, 1919-1920. [CrossRef]

111. Muñoz-Sanz, J.V.; Zuriaga, E.; López, I.; Badenes, M.L.; Romero, C. Self-(in)compatibility in apricot germplasm is controlled by two major loci, $S$ and M. BMC Plant. Biol. 2017, 17, 82. [CrossRef]

112. Corrin, A.A. “Ruby” Apricot Tree. United. States Patent USPP8177, 16 March 1993.

113. Zaiger, C.F. Apricot Tree (Spring Giant). United. States Patent USPP5138, 15 November 1983. 
114. Dicenta, F.; Audergon, J.M. Inheritance of resistance to plum pox potyvirus (PPV) in 'Stella' apricot seedlings. Plant. Breed. 1998, 117, 579-581. [CrossRef]

115. Tartarini, S.; Sansavini, S.; Vinatzer, B.; Gennari, F.; Domizi, C. Efficiency of marker assisted selection (MAS) for the Vf scab resistance gene. Acta Hortic. 2000, 538, 549-552. [CrossRef]

(C) 2020 by the authors. Licensee MDPI, Basel, Switzerland. This article is an open access article distributed under the terms and conditions of the Creative Commons Attribution (CC BY) license (http://creativecommons.org/licenses/by/4.0/). 